\title{
OPEN New Cretaceous antlion-like lacewings promote a phylogenetic reappraisal of the extinct myrmeleontoid family Babinskaiidae
}

\begin{abstract}
Xiumei Lu ${ }^{1 \bowtie}$, Bo Wang ${ }^{2}$ \& Xingyue Liu ${ }^{3 凶}$
Babinskaiidae is an extinct family of the lacewing superfamily Myrmeleontoidea, currently only recorded from the Cretaceous. The phylogenetic position of this family is elusive, with inconsistent inferences in previous studies. Here we report on three new genera and species of Babinskaiidae from the mid-Cretaceous Kachin amber of Myanmar, namely Calobabinskaia xiai gen. et sp. nov., Stenobabinskaia punctata gen. et sp. nov., and Xiaobabinskaia lepidotricha gen. et sp. nov. These new babinskaiids are featured by having specialized characters, such as the rich number of presectoral crossveins and the presence of scaly setae on forewing costal vein, which have not yet been found in this family. The exquisite preservation of the Kachin amber babinskaiids facilitate a reappraisal of the phylogenetic placement of this family based on adult morphological characters. Our result from the phylogenetic inference combining the data from fossil and extant myrmeleontoids recovered a monophyletic clade composed of Babinskaiidae and another extinct family Cratosmylidae, and further assigned this clade to be sister group to a clade including Nemopteridae, Palaeoleontidae, and Myrmeleontidae. Babinskaiidae appears to be a transitional lineage between Nymphidae and advanced myrmeleontoids, with ancient morphological diversification.
\end{abstract}

Babinskaiidae is an extinct lacewing family belonging to the superfamily Myrmeleontoidea, presently known with 13 species in nine genera ${ }^{1}$. The adults of Babinskaiidae are diagnosed by a combination of characters, including the filiform antennae, the presence of trichosors, the origin of RP + MA far distal to wing base, the presence of presectoral crossveins in both fore- and hind wings, and the reduction of hind wing A2 and A3 veins.

Babinskaiidae to date is only recorded from the Cretaceous, lasting a timespan of ca. 35 million years from the Barremian to the Cenomanian. Besides a single species from the Lower Cretaceous Zaza Formation of Russia, all the other babinskaiids known are found from the Lower Cretaceous Crato Formation of Brazil, and the mid-Cretaceous Kachin amber of northern Myanmar ${ }^{2-11}$, suggesting richer species diversity of this family from the Gondwanan landmasses. Notably, more than a half of known species of Babinskaiidae (seven species in six genera) come from the mid-Cretaceous Kachin amber ${ }^{1}$ (Table S1).

Despite definite myrmeleontoid affinity, the phylogenetic position of Babinskaiidae within Myrmeleontoidea is still elusive ${ }^{7}$. This family was originally established as a subfamily of Nymphidae (split-footed lacewings) ${ }^{2}$, and subsequently elevated to an independent family ${ }^{12}$. Martins-Neto ${ }^{13,14}$ postulated that Babinskaiidae is sister to a myrmeleontoid clade including Ascalaphidae + (Nemopteridae + (Araripeneuridae + (Palaeoleontidae + Myrmeleontidae))) in a phylogenetic analysis primarily based on fossil taxa of Myrmeleontoidea from the Lower Cretaceous of Brazil. Similar result was also obtained in Yang et al. ${ }^{15}$. However, Makarkin et al. ${ }^{7}$ divided Myrmeleontoidea into two epifamilies, i.e., Nymphidoidae and Myrmeleontoidae, and assigned Babinskaiidae together with Nymphidae into Nymphidoidae based on the presence of trichosors and the long MP that is not fused with CuA.

${ }^{1}$ Institute of Ecological and Environmental Protection, Shanghai Academy of Agricultural Sciences, Shanghai 201403, China. ${ }^{2}$ State Key Laboratory of Palaeobiology and Stratigraphy, Nanjing Institute of Geology and Palaeontology and Center for Excellence in Life and Paleoenvironment, Chinese Academy of Sciences, 39 East Beijing Road, Nanjing 210008, China. ${ }^{3}$ Department of Entomology, China Agricultural University, Beijing 100193, China. ${ }^{\square}$ email: Ixm2361892563@126.com; liuxingyue@cau.edu.cn 
Here we describe three new species of Babinskaiidae, each representing a new genus, from the mid-Cretaceous of Myanmar, namely Calobabinskaia xiai gen. et sp. nov., Stenobabinskaia punctata gen. et sp. nov., and Xiaobabinskaia lepidotricha gen. et sp. nov. Remarkably, some specialized morphological characters are found in these new babinskaiids, such as the split arolium, the rich number of presectoral crossveins, and the presence of scaly setae on forewing, which highlight the morphological diversity of this extinct myrmeleontoid family. With the present finding, a broad spectrum of babinskaiid taxa is available for evaluating the phylogenetic position of this family. As such, a phylogenetic inference on the relationships among fossil and extant families of Myrmeleontoidea is performed based on adult morphological characters. Our results shed light on the early evolution of Myrmeleontoidea, an advanced clade of lacewings.

\section{Results}

Systematic palaeontology. Class Insecta Linnaeus, 1758

Order Neuroptera Linnaeus, 1758

Superfamily Myrmeleontoidea Latreille, 1802

\section{Family Babinskaiidae Martins-Neto and Vulcano, 1989}

Type genus: Babinskaia Martins-Neto and Vulcano, 1989

Revised diagnosis (1) Antenna filiform, longer than half of forewing length; (2) wings slenderly elongate, slightly broadened distad in most genera; (3) fore- and hind wing similar in shape and size, but hind wing sometimes strongly narrowed; (4) nygmata absent; (5) trichosors present along wing margin of both fore- and hind wings; (6) forewing 1r-m absent; (7) origin of RP + MA far distal to wing base, around midpoint of wing; (8) a long hypostigmal cell present; (9) several presectoral crossveins present in both fore- and hind wings; (10) MP single, pectinately branched in most genera; (11) forewing oblique vein absent between MP and CuA; (12) forewing $\mathrm{CuA}$ running parallel with posterior margin for a long distance; (13) forewing CuP fused with A1, or connected A1 by a short crossvein, or approximating A1 without any crossvein; (14) hind wing anal space very small, with reduced $\mathrm{A} 3$.

\section{Genus Calobabinskaia gen. nov.}

(Figs. 1, 2, 3)

LSID: urn:lsid:zoobank.org:act:E84839F7-DFB7-4978-A835-16001DF964B0

Type species: Calobabinskaia xiai sp. nov

Diagnosis The new genus can be distinguished from the other genera of Babinskaiidae by a combination of the following characters: (1) large-sized babinskaiids, with forewing length ca. $22 \mathrm{~mm}$ [shared by Gigantobabinskaia Makarkin and Staniczek ${ }^{10}$ and Stenobabinskaia gen. nov., but slightly longer than these two genera; 9-15 $\mathrm{mm}$ in remaining genera]; (2) wings strongly narrowed, ca. 6.5 times as long as wide [shared by Stenobabinskaia gen. nov.; 4.5 times as long as wide in most genera]; (3) apex of antenna slightly dilated distally [antenna without dilated apex in the remaining genera with preserved antenna]; (4) forewing costal space strongly narrowed, almost as wide as subcostal space [shared by Stenobabinskaia gen. nov.; 2-3 times as wide as subcostal space in the other genera]; (5) numerous crossveins present in most part of wing except RP space in both wings [shared by Stenobabinskaia gen. nov.; crossveins much fewer in the other genera]; (6) 19 presectoral crossveins present in fore- and hind wings [10-11 in Stenobabinskaia gen. nov.; forewing with 4-7 presectoral crossveins and hind wing with 1-5 presectoral crossveins in most genera]; (7) RP + MA originating slightly distal to midpoint of wing in both wings [proximal to midpoint of wing in most genera; at midpoint of wing in Neliana Martins-Neto ${ }^{12}$ and Pseudobabinskaia Makarkin et al. ${ }^{7}$; distal to midpoint of wing in Calobabinskaia gen. nov.; unknown in Burmobabinskaia Lu et al. ${ }^{6}$; (8) several RP branches fused with neighboring branches, especially in forewing [shared by Stenobabinskaia gen. nov.; absent in the other genera]; (9) one gradate series of crossveins present in forewing [shared by most babinskaiid genera; two or more series in Stenobabinskaia gen. nov. and Xiaobabinskaia gen. nov.]; (10) forewing $\mathrm{CuP}$ and hind wing $\mathrm{CuA}$ extremely long, terminating posterior to midpoint of hind margin [shared by Stenobabinskaia gen. nov.; relatively short, terminating at midpoint of hind margin in Xiaobabinskaia gen. nov.; much shorter, terminating proximal to midpoint of hind margin in most genera]; (11) forewing A1 proximally fused with CuP [shared by Pseudoneliana Huang et al. ${ }^{9}$, Stenobabinskaia gen. nov. and Xiaobabinskaia gen. nov.; proximally separated with each other in the other genera with preserved anal veins]; (12) arolium bilobed [simple or unknown in the other genera].

Etymology From “Calo-" (Greek, meaning "beautiful”) and "babinskaia” (the type genus-name of Babinskaiidae), in reference to the beautifully preserved material of this new genus with remarkable characters in Babinskaiidae. Gender: Feminine.

Remarks The new genus is placed in Babinskaiidae based on the presence of trichosors and multiple presectoral crossveins in both fore- and hind wings. The new genus is among the large-sized babinskaiids, together with Gigantobabinskaia and Stenobabinskaia gen. nov, with forewing length over $20 \mathrm{~mm}$. However, it can be easily distinguished from Gigantobabinskaia by the narrowed wings, the presence of more than 15 presectoral crossveins, and the origin of RP + MA distal to midpoint of wing. The new genus is similar to Stenobabinskaia gen. nov. by the distinctly elongated wings, the presence of multiple presectoral crossveins, the bifurcated $\mathrm{CuA}$ branches in 


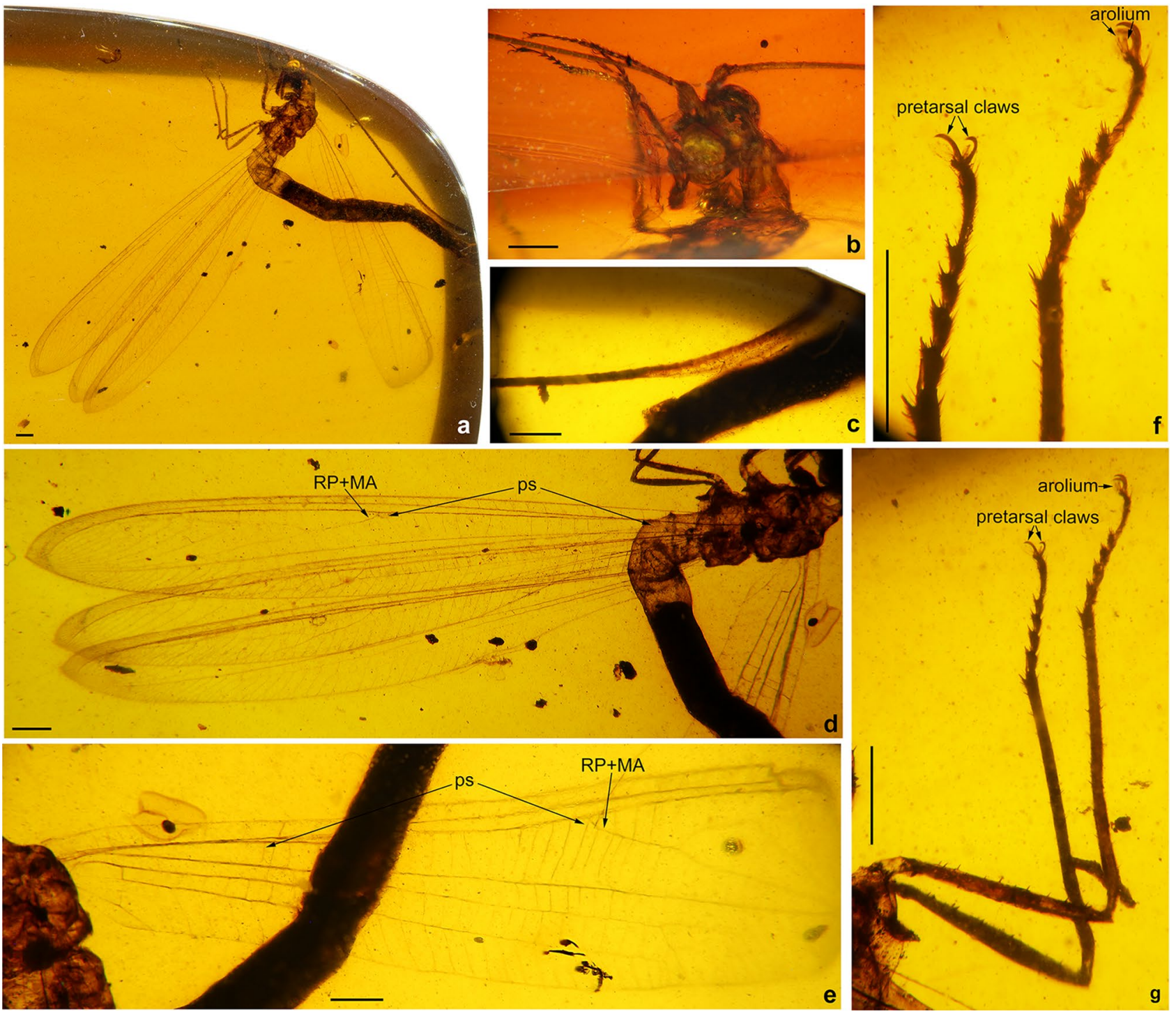

Figure 1. Calobabinskaia xiai sp. nov., holotype female. (a) habitus photograph, dorsolateral view; (b) photograph of head, dorsolateral view; (c) photograph of antennal apex; (d) photograph of left wings; (e) photograph of right forewing; (f) photograph of metatarsi; (g) photograph of hind legs. Scale bar $=1.0 \mathrm{~mm}$.

the forewing and the long $\mathrm{CuP}$ in the hind wing, but it differs from the latter genus by the fewer branches of RP and sparse crossveins in RP space, as well as the more distad origin of RP + MA.

\section{Calobabinskaia xiai sp. nov.}

(Figs. 1, 2, 3)

LSID: urn:lsid:zoobank.org:act:1CD4D82D-DCCE-40BD-A56D-A9A32DA1B783

Diagnosis Same as for the genus.

Description Body length $25.63 \mathrm{~mm}$; head $1.78 \mathrm{~mm}$ long, $0.76 \mathrm{~mm}$ wide; antenna length $19.11 \mathrm{~mm}$; diameter of compound eye $0.81 \mathrm{~mm}$; forewing $22.28 \mathrm{~mm}$ long, $3.40 \mathrm{~mm}$ wide; hind wing $20.74 \mathrm{~mm}$ long, $3.09 \mathrm{~mm}$ wide; abdomen length $18.52 \mathrm{~mm}$.

Head with vertex medially domed; compound eyes large, semi-globular; antenna filiform, more than half of forewing length, slightly dilated distally; pedicel almost as long as but slightly narrower than scape.

Prothorax slender, longer than wide; meso- and metathorax robust. Wings strongly narrowed, ca. 6.5 times as long as wide, transparent and immaculate; single trichosor present between veins along distal margin in both fore- and hind wings.

Forewing: Costal space distinctly narrowed, almost as wide as subcostal space, but narrower than radial space, with 40 simple crossveins on proximal 4/5, and 26 crossveins and veinlets of ScP + RA on distal 1/5, which are mostly forked marginally; subcostal crossveins absent; 19 presectoral crossveins present; RP + MA originated 

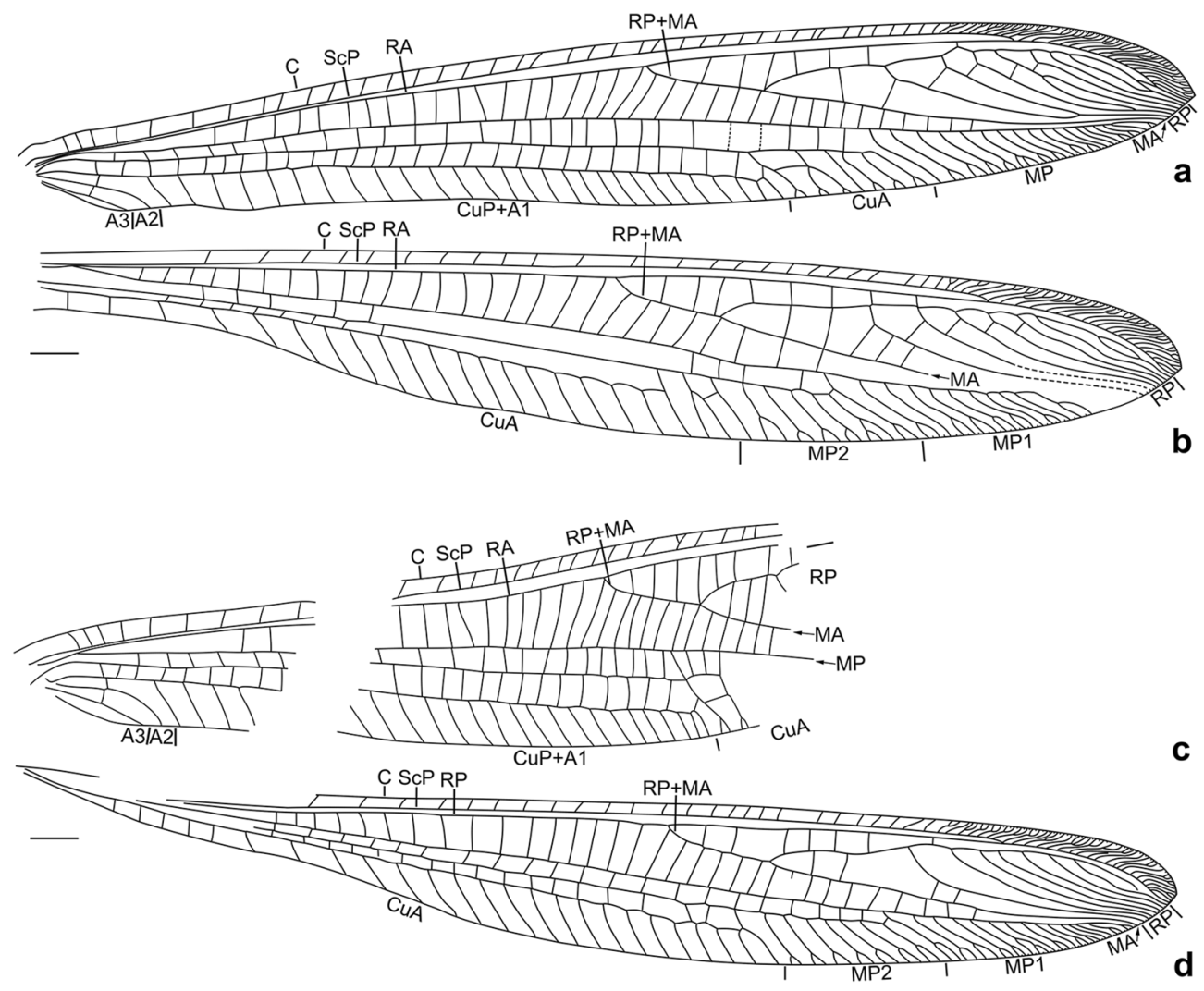

Figure 2. Calobabinskaia xiai sp. nov., holotype female. (a) drawing of left forewing (drawn by XML); (b) drawing of left hind wing (drawn by XML); (c) drawing of right forewing (drawn by XML); (d) drawing of right hind wing (drawn by XML). Scale bar $=1.0 \mathrm{~mm}$.
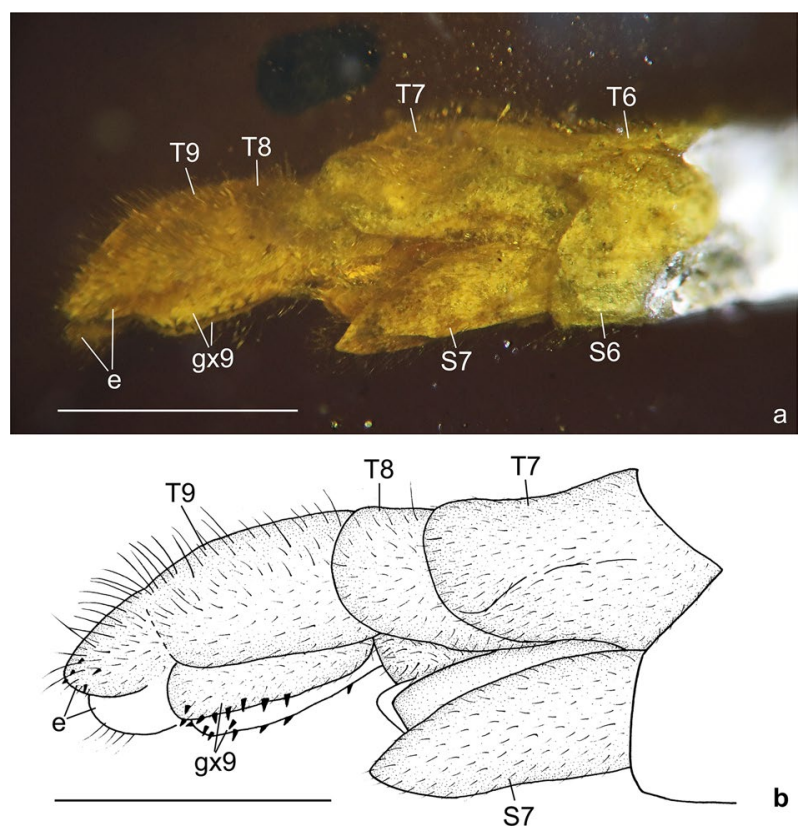

Figure 3. Calobabinskaia xiai sp. nov., holotype female. (a) photograph of genitalia, lateral view; (b) drawing of genitalia, lateral view (drawn by XML). Scale bar $=1.0 \mathrm{~mm}$. 
from R slightly distal to midpoint of wing; RP pectinately branched from its proximal 1/3, with one rp-ma crossvein in left forewing and three in right forewing between stem of RP and MA; RP with eight branches, mostly simple, but RP4 deeply forked; RP1 fused with RP2 distally, RP3 fused with anterior branch of RP4 distally, RP7 fused with RP8 distally; one gradate series of four crossveins present near branching points of RP branches; MA simple; MP long and nearly straight, pectinately branched from distal 1/4, with 18 branches, mostly bearing a marginal fork; 27 crossveins present between $\mathrm{MP}$ and $\mathrm{CuA} ; \mathrm{CuA}$ and $\mathrm{CuP}$ diverging near wing base; $\mathrm{CuA}$ pectinately branched, with six branches, mostly bearing a marginal fork; CuP long, proximally fused with A1, terminating at same level of diverging point between RP and MA, with 28 pectinate, short and simple branches; 29 cua-cup crossveins present; A2 and A3 simple, connected with each other by a short a2-a 3 crossvein.

Hind wing: Proximally distinctly narrowed, remaining part nearly as wide as forewing; costal space slightly wider than subcostal space, with at least 24 simple crossveins on proximal 4/5, and 25 crossveins and veinlets of ScP + RA on distal 1/5; subcostal crossveins absent; 19 presectoral crossveins present; $\mathrm{RP}+\mathrm{MA}$ originating distal to midpoint of wing; two rp-ma crossveins present between stem of RP and MA; RP pectinately branched from its proximal 1/3 into eight simple branches, with distal-most two ones fused distally; one gradate series of four crossveins present near branching points of RP branches; MP1 and MP2 straight and long, both pectinately branched from distal 1/5, respectively with 15 and seven branches, mostly bearing a marginal fork; CuA long, terminating at same level of diverging point between MA and RP, with ca. 25 pectinate simple branches.

Legs slender, with sparse short setae; tarsus 5-segmented; tarsomeres 1-4 gradually shortened; tarsomere 5 longest, almost as long as combined length of tarsomeres 2-4; pretarsal claws curved, equal in length and shape, with a bilobed arolium.

Abdomen slender and elongate, gradually narrowed distally up to genitalia. Tergum 7 and sternum 7 broad, nearly equal in length, sternum 7 distinctly tapered posteriorly. Genitalia: Tergum 8 very short and narrower than tergum 9; no distinct gonocoxites 8 discernible; tergum 9 longer than tergum 8; a pair of narrow valvate gonocoxites 9 present, bearing a row of teeth along ventral margin; ectoprocts paired, small, with apex slightly tapered; callus cerci not discernible.

Etymology The new species is dedicated to Mr. Fangyuan Xia, who kindly offered the specimen (the holotype) of this new species for present study.

Type material Holotype: LPAM BA-NEU-002. Amber piece preserving a nearly complete female adult of Calobabinskaia xiai gen. et sp. nov. It is polished in the form of a flattened elliptical cabochon, clear and transparent, with length $\times$ width $53.47 \times 37.55 \mathrm{~mm}$, height $15.38 \mathrm{~mm}$.

\section{Genus Stenobabinskaia gen. nov.}

(Figs. 4, 5, 6)

LSID: urn:lsid:zoobank.org:act:51AA6FFE-3BA6-4828-9E69-ACEC94A1A125

Type species: Stenobabinskaia punctata sp. nov.

Diagnosis The new genus can be distinguished from the other genera of Babinskaiidae by a combination of the following characters: (1) large-sized babinskaiids, with forewing length ca. $20 \mathrm{~mm}$ [shared by Gigantobabinskaia and Calobabinskaia gen. nov., but slightly shorter than these two genera; 9-15 $\mathrm{mm}$ in the other genera]; (2) wings strongly narrowed, ca. 6.5 times as long as wide [shared by Calobabinskaia gen. nov.; 4.5 times as long as wide in most genera]; (3) forewing costal space strongly narrowed, slightly wider than subcostal space [shared by Calobabinskaia gen. nov.; 2-3 times as wide as subcostal space in the other genera]; (4) crossveins densely spaced in both wings [shared by Calobabinskaia gen. nov.; much fewer in the other genera]; (5) at least 10-11 presectoral crossveins present in fore- and hind wings, with one of them distinctly sigmoid [19 in Calobabinskaia gen. nov.; 4-7 in most genera; no sigmoid presectoral crossvein in the other genera]; (6) RP + MA originating slightly proximal to midpoint of wing [shared by most genera; at midpoint of wing in Neliana and Pseudobabinskaia; distal to midpoint of wing in Calobabinskaia gen. nov.; unknown in Burmobabinskaia]; (7) several RP branches fused with neighboring branches, especially in forewing [shared by Calobabinskaia gen. nov.; absent in the other genera]; (8) forewing with three gradate series of crossveins [one gradate series present in most genera; more than three gradate series present in Xiaobabinskaia gen. nov.]; (9) forewing CuP and hind wing CuA extremely long, terminating posterial to midpoint of hind margin [shared by Calobabinskaia gen. nov.; relatively short, terminating at midpoint of hind margin in Xiaobabinskaia gen. nov.; much shorter, terminating proximad midpoint of hind margin in most genera]; (10) forewing A1 fused with CuP [shared by Pseudoneliana, Calobabinskaia gen. nov. and Xiaobabinskaia gen. nov.; separated from each other in the other genera with preserved anal veins].

Etymology From "Steno-" (Greek, meaning "narrow") and "babinskaia” (the type genus-name of Babinskaiidae) in reference to the narrowly elongate wings in the new genus. Gender: Feminine.

Remarks The new genus resembles Calobabinskaia gen. nov., and the morphological comparison can be seen in the Remarks section of Calobabinskaia gen. nov.

Stenobabinskaia punctata sp. nov.

(Figs. 4, 5, 6)

LSID: urn:lsid:zoobank.org:act:8235C299-9B3B-4319-A826-30FCFC1F5A89 


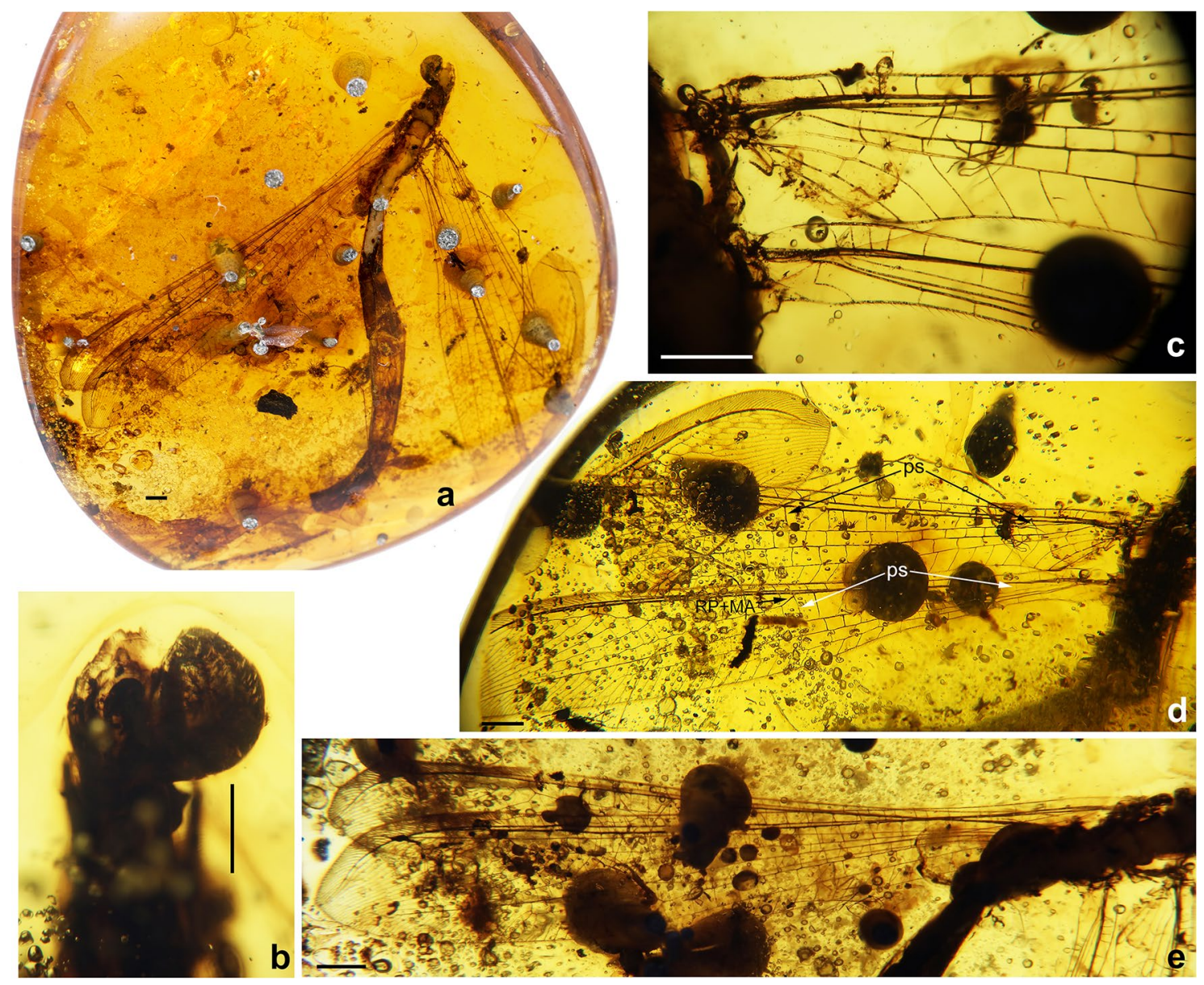

Figure 4. Stenobabinskaia punctata sp. nov., holotype male. (a) habitus photograph, dorsal view; (b) photograph of head and prothorax, dorsal view; (c) photograph of bases of right wings; (d) photograph of right wings; (e) photograph of left wings. Scale bar $=1.0 \mathrm{~mm}$.

Diagnosis Same as for the genus, besides dark spots present at distal 1/3 of both fore- and hind wings, mostly on crossveins between RP branches.

Description Male. Body length $23.09 \mathrm{~mm}$; head $1.34 \mathrm{~mm}$ long, $1.84 \mathrm{~mm}$ wide; diameter of compound eye $1.17 \mathrm{~mm}$; forewing $20.07 \mathrm{~mm}$ long, $3.11 \mathrm{~mm}$ wide; hind wing $18.41 \mathrm{~mm}$ long, $2.72 \mathrm{~mm}$ wide; abdomen length $17.91 \mathrm{~mm}$.

Head with vertex medially domed; compound eyes large, semi-globular; antenna not preserved.

Prothorax much narrower than head, slightly wider than long; meso- and metathorax slightly wider than prothorax. Wings narrowly elongate, ca. 6.5 times as long as wide; wing spots present on apex of both fore- and hind wings, mostly on some crossveins of branching region of RP; single trichosor present between veins along distal margin in both fore- and hind wings.

Forewing: Costal space strongly narrowed, slightly wider than subcostal space, but narrower than radial space, with ca. 30 simple crossveins on proximal 3/4, and ca. 45 crossveins and veinlets of $\mathrm{ScP}+\mathrm{RA}$ on distal 1/4, mostly forked marginally; subcostal crossveins absent; 11 presectoral crossveins present, one of them sigmoid and acutely angled with R; RP + MA originated from R slightly proximal to midpoint of wing; RP pectinately branched from its proximal 1/5, with one rp-ma crossvein between stem of RP and MA; RP with 13 branches, mostly simple, but RP5 and RP6 deeply forked; RP8 and RP9, RP12 and RP13 fused distally; at least four gradate series of crossveins present among branches of RP and MA at proximal half; an additional distal gradate series of crossveins present; MA only with a marginal fork; MP long and nearly straight, pectinately branched from distal 1/4, with 17 branches, mostly bearing a marginal fork; 22 crossveins present between MP and $\mathrm{CuA}$; $\mathrm{CuA}$ and $\mathrm{CuP}$ diverging near wing base; $\mathrm{CuA}$ pectinately branched, with at least 10 branches, most of which are simple; $\mathrm{CuP}$ long, proximally fused with A1, terminating at same level of diverging point between RP and MA, pectinately branched with at least 23 short and simple branches; 18 cua-cup crossveins present; A2 and A3 simple, connected with each other by a short a2-a3 crossvein.

Hind wing: Proximally distinctly narrowed, remaining part nearly as wide as forewing; costal space narrow, nearly twice as wide as subcostal space, with at least 28 crossveins on proximal $3 / 4$, and 45 crossveins and veinlets of ScP + RA on distal 1/4, mostly forked marginally; subcostal crossveins absent; at least 10 presectoral crossveins present, one of them sigmoid and acutely angled with R; RP + MA originating slightly proximal to midpoint of 

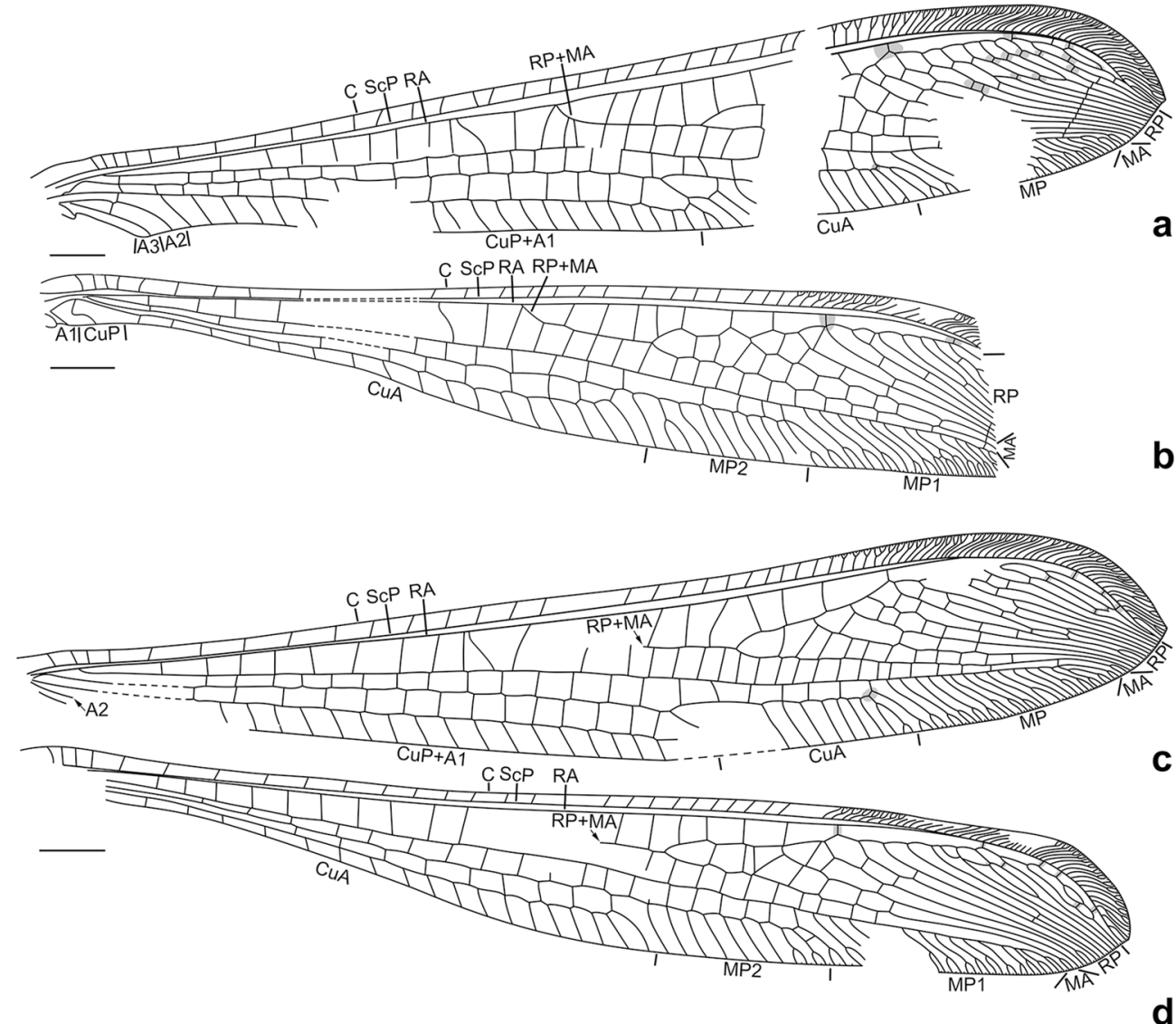

Figure 5. Stenobabinskaia punctata sp. nov., holotype male. (a) drawing of left forewing (drawn by XML); (b) drawing of left hind wing (drawn by XML); (c) drawing of right forewing (drawn by XML); (d) drawing of right hind wing (drawn by XML). Scale bar $=1.0 \mathrm{~mm}$.

wing; RP pectinately branched from its proximal 1/5 into 13 mostly simple branches, with RP3 bearing a marginal fork; two rp-ma crossveins present in left forewing and three in right wing between stem of RP and MA; RP7 touched with RP8 at a point basally; RP8 and RP9 fused into a loop; RP12 and RP13 fused distally, then fused with R11 distally; at least two gradate series of crossveins present among branches of RP and MA at proximal half; an additional distal gradate series of crossveins present; MP1 and MP2 diverging near wing base, straight and long, both pectinately branched from its distal 1/4; MP1 with 15 branches, mostly marginally forked; MP2 with nine branches, mostly simple; $\mathrm{CuA}$ and $\mathrm{CuP}$ diverging near wing base; $\mathrm{CuA}$ long, terminating at same level of branching point between RP and MA, pectinately branched with 17 simple branches; CuP strongly sigmoid proximally, simple; A1 short and simple.

Legs not preserved.

Abdomen slenderly elongate, with segments 4-5 slightly widened. Male genitalia: Tergum 9 slightly shorter than tergum 8; sternum 9 large, about twice as long as tergum 9 plus ectoproct, straightly extending posteriad; putative gonocoxite 9 present, but probably detached from its original position, strongly curved medially with acute tip; putative gonostyli 11 present as a pair of long spinous sclerites, which are slightly shorter than sternum 9; ectoprocts paired, subtrapezoidal in lateral view, with large ovoid callus cerci, and distally with some short teeth.

Etymology The specific epithet "punctata" refers to the occurrence of wing spots in the new species.

Type material Holotype: NIGP176251. Amber piece preserving a nearly complete male adult of Stenobabinskaia punctata gen. et sp. nov. It is polished in the form of a flattened triangular cabochon, clear and transparent, with lengths of three sides $29.65 \times 28.71 \times 26.23 \mathrm{~mm}$, height $7.07 \mathrm{~mm}$.

\section{Genus Xiaobabinskaia gen. nov.}

(Figs. 7, 8, 9)

LSID: urn:lsid:zoobank.org:act:0D29E44C-7C2D-47DD-A070-657F25B81ACE

Type species: Xiaobabinskaia lepidotricha sp. nov. 

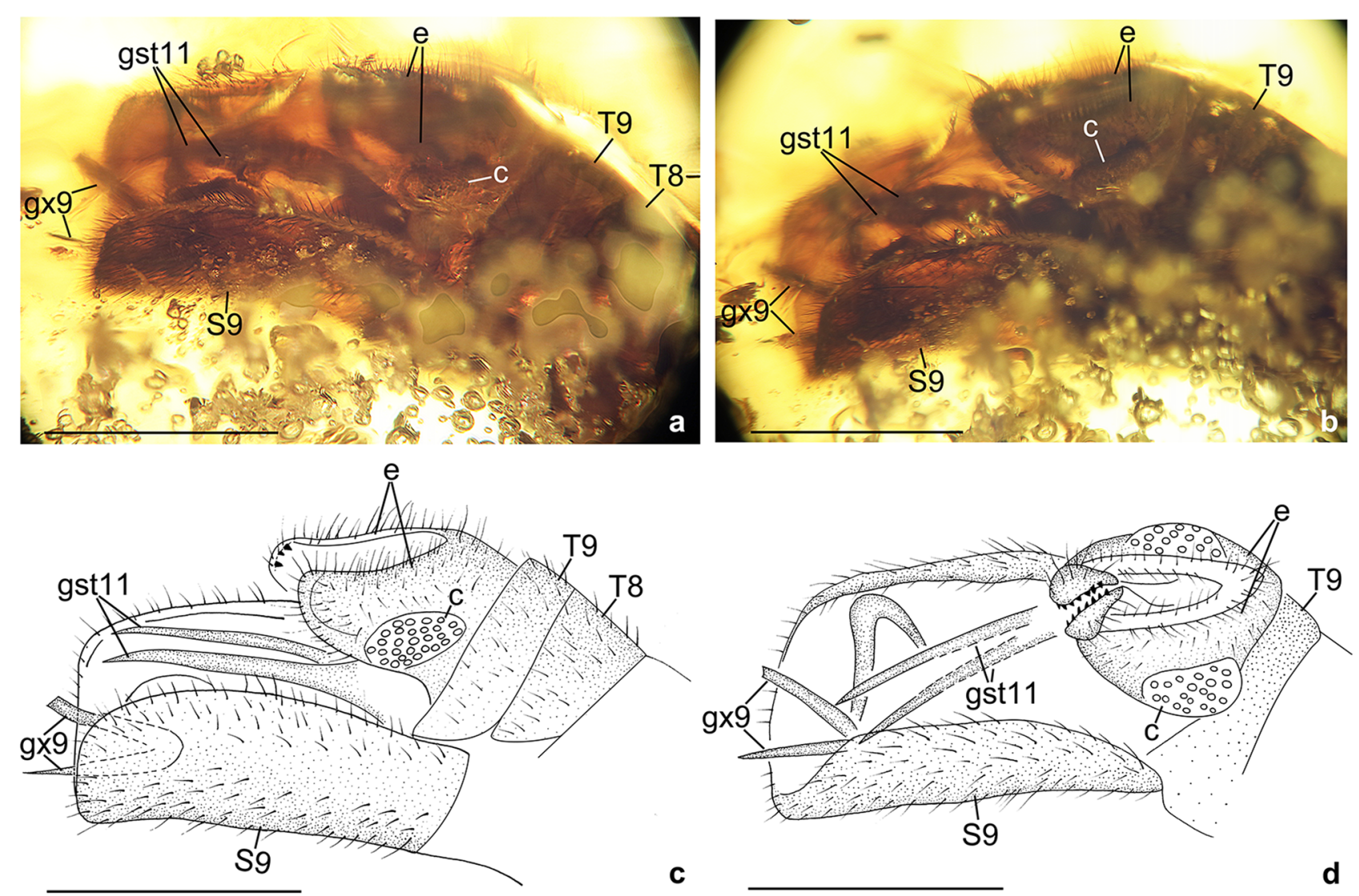

Figure 6. Stenobabinskaia punctata sp. nov., holotype male. (a) photograph of genitalia, lateral view; (b) photograph of genitalia, dorsal view; (c) drawing of genitalia, lateral view (drawn by XML); (d) drawing of genitalia, dorsal view (drawn by XML). Scale bar $=1.0 \mathrm{~mm}$.

Diagnosis The new genus can be distinguished from the other genera of Babinskaiidae by a combination of the following characters: (1) medium-sized babinskaiids, with forewing length ca. $15 \mathrm{~mm}$ [ca. 10-13 mm in most genera of Babinskaiidae; more than $20 \mathrm{~mm}$ in Gigantobabinskaia, Calobabinskaia gen. nov. and Stenobabinskaia gen. nov.]; (2) a row of scaly setae present on proximal section of forewing costal vein, and a number of thick setae present along proximal sections of forewing ScP, MP, and A1 [no specialized setae on forewing veins in the other Kachin amber babinskaiids; unknown in genera preserved as compression fossils]; (3) hind wing with apex acutely tapered and slightly curved posteriad [shared by Electrobabinskaia Lu et al. ${ }^{6}$; feebly tapered in the other genera]; (4) six presectoral crossveins present in forewing, and at least five presectoral crossveins present in hind wing [forewing with 4-7 presectoral crossveins and hind wing with 1-5 presectoral crossveins in most genera; more than 10 presectoral crossveins present in Calobabinskaia gen. nov. and Stenobabinskaia gen. nov.]; (5) RP + MA originating at proximal $1 / 3$ of wing in both fore- and hind wings [shared by Electrobabinskaia and Gigantobabinskaia; slightly shifted distad although still proximal to midpoint of wing in most genera; at midpoint of wing in Neliana and Pseudobabinskaia; distal to midpoint of wing in Calobabinskaia gen. nov.; unknown in Burmobabinskaia]; (6) RP with eight branches in both fore- and hind wings [shared by Calobabinskaia gen. nov. and Electrobabinskaia; 3-5 RP branches in most genera; more than 10 RP branches in Gigantobabinskaia and Stenobabinskaia gen. nov.]; (7) forewing with 15 or more crossveins among branches of RP and MA on proximal half [shared by Stenobabinskaia gen. nov.; forewing with 10 or less corresponding crossveins in most genera]; (8) a distal gradate series of crossveins present in both fore- and hind wings [shared by Baisonelia Ponomarenko ${ }^{4}$, Parababinskaia Makarkin et al. ${ }^{7}$, Electrobabinskaia, Gigantobabinskaia, Stenobabinskaia gen. nov.; absent in Babinskaia Martins-Neto and Vulcano ${ }^{2}$, Calobabinskaia gen. nov., Neliana and Pseudobabinskaia; unknown in the other genera]; (9) forewing $\mathrm{CuP}$ and hind wing $\mathrm{CuA}$ long, terminating at midpoint of hind margin [extremely long, terminating posterior to midpoint of hind margin in Calobabinskaia gen. nov. and Stenobabinskaia gen. nov.; much shorter, terminating proximad midpoint of hind margin in most genera]; (10) forewing A1 proximally fused with $\mathrm{CuP}, \mathrm{A} 2$ approximating stem of A1 and distally abruptly curved posteriad [similar to Pseudobabinskaia, but A1 not fused with CuP; A2 and/or A3 relatively long and not curved posteriad in the other genera with $\mathrm{CuP}$ and Al fused].

Etymology From "Xiao-" and "Babinskaia" (the type genus-group name of Babinskaiidae) in reference to Mrs. Xiao Jia, who kindly offered the specimen (the holotype) of the genus type for our study. Gender: Feminine. 


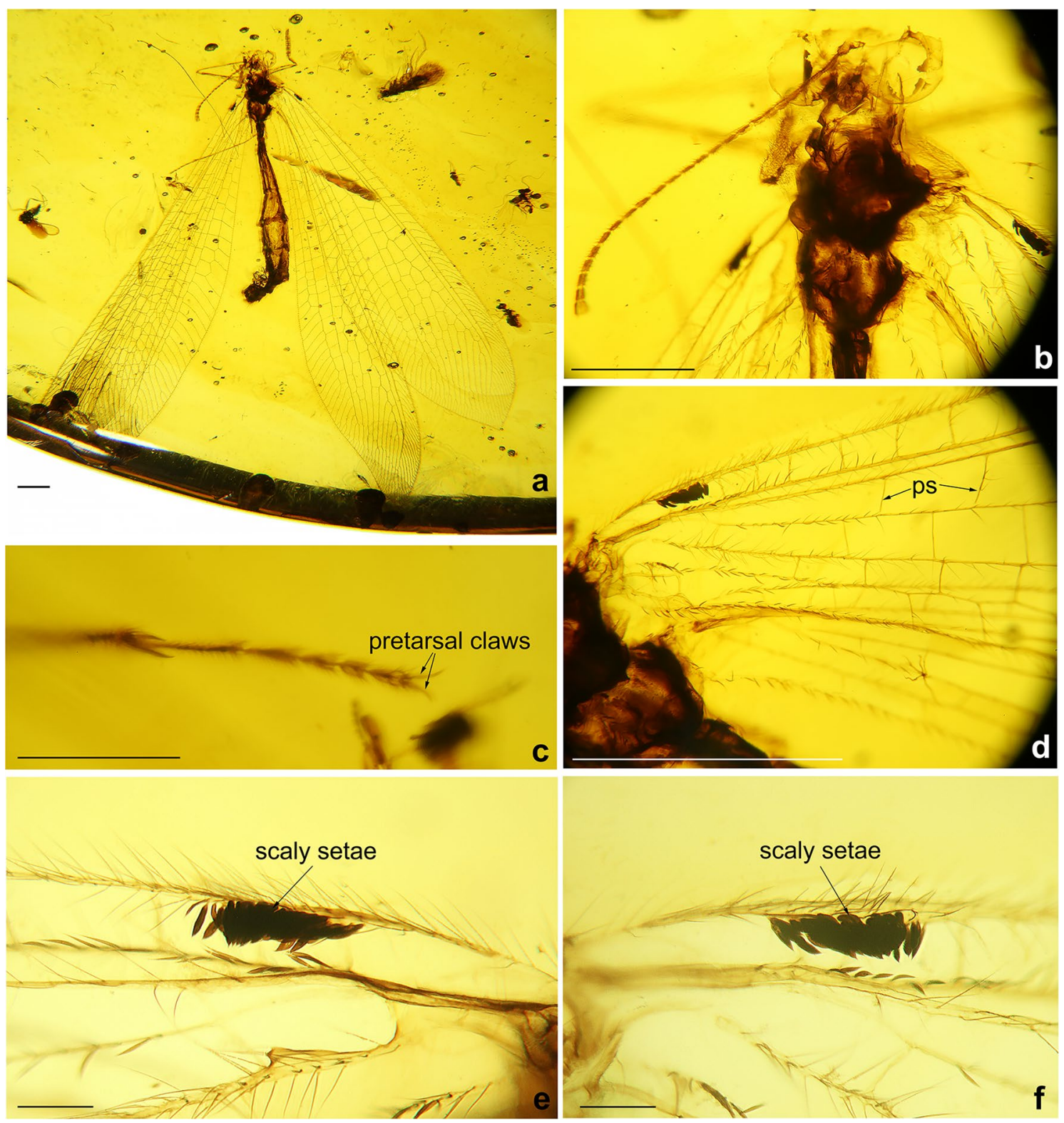

Figure 7. Xiaobabinskaia lepidotricha sp. nov., holotype female. (a) habitus photograph, dorsal view; (b) photograph of head and prothorax, dorsal view; (c) photograph of tarsus; (d) photograph of bases of right wings; (e) photograph of costal scaly setae in left forewing; (f) photograph of costal scaly setae in right forewing. Scale bar $=1.0 \mathrm{~mm}$.

Remarks The new genus resembles Electrobabinskaia and Gigantobabinskaia by the presence of distal gradate series of crossveins in both fore- and hind wings and the apex acutely tapered and curved posteriad in hind wing. However, it differs from the latter two genera by the presence of a row of scaly setae on proximal section of the forewing costal vein, the dense crossveins among branches of RP + MA, and the forewing A1 proximally fused with CuP. Besides, the new genus differs from Electrobabinskaia by the larger body size, the simple CuA branches, and the elongate $\mathrm{CuP}$ in the forewing, and it differs from Gigantobabinskaia by the smaller body size and the sparser RP branches.

\section{Xiaobabinskaia lepidotricha sp. nov.}

(Figs. 7, 8, 9)

LSID: urn:lsid:zoobank.org:act:AD9E972D-9EBA-4C9A-8C63-DC017B75C994

Diagnosis Same as for the genus. 

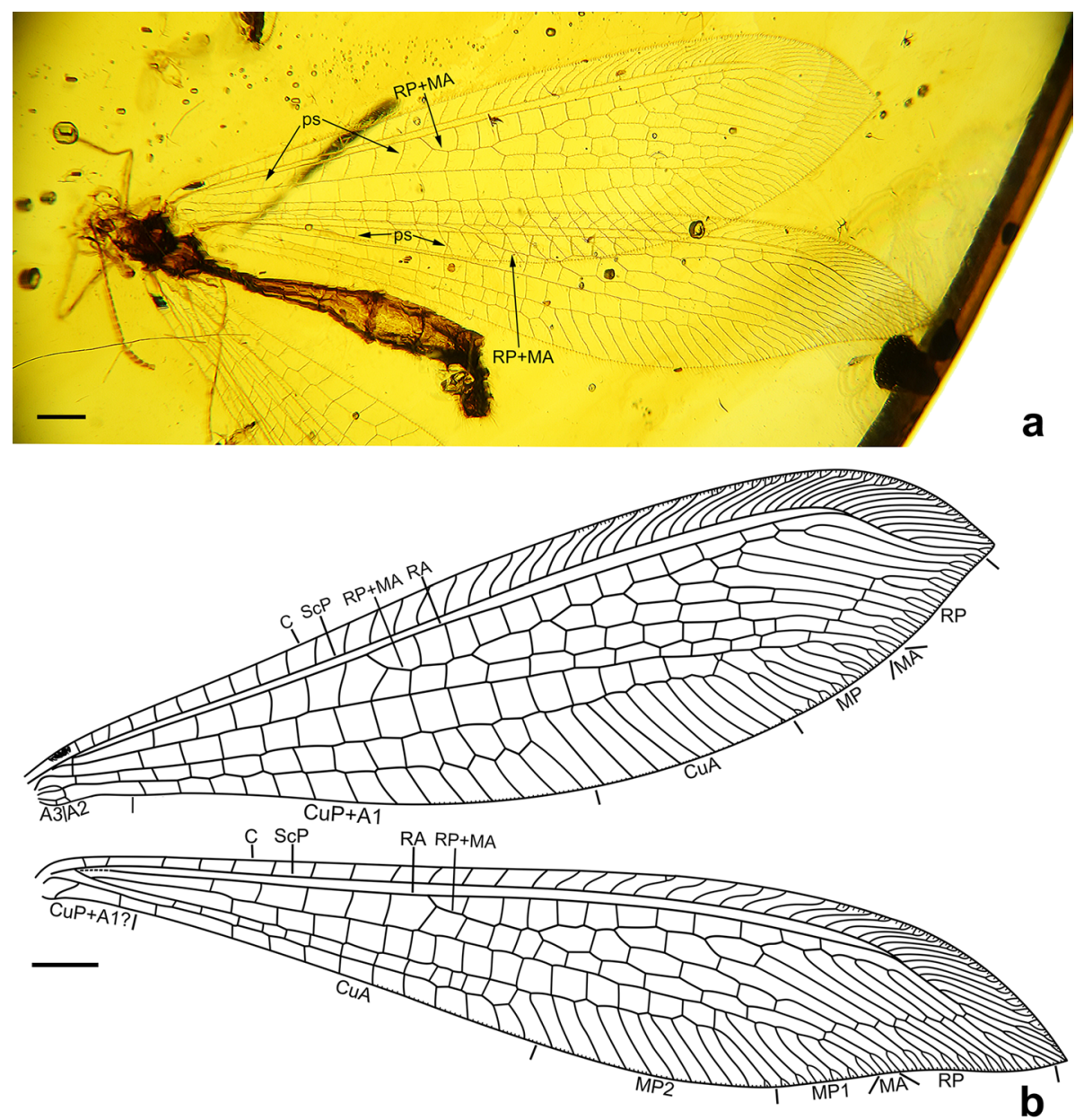

Figure 8. Xiaobabinskaia lepidotricha sp. nov., holotype female. (a) photograph of right wings; (b) drawing of right wings (drawn by XML). Scale bar $=1.0 \mathrm{~mm}$.

Description Female. Body length $10.76 \mathrm{~mm}$; head $0.67 \mathrm{~mm}$ long, $1.51 \mathrm{~mm}$ wide; incomplate antenna length $3.40 \mathrm{~mm}$; diameter of compound eye $0.68 \mathrm{~mm}$; forewing $15.48 \mathrm{~mm}$ long, $4.19 \mathrm{~mm}$ wide; hind wing $15.92 \mathrm{~mm}$ long, $3.31 \mathrm{~mm}$ wide; abdomen length $10.00 \mathrm{~mm}$.

Head with vertex medially domed; compound eyes large, semi-globular; antenna partly preserved; scape much wider and slightly longer than pedicel; flagellum with 22 flagellomeres preserved, each flagellomere distinctly shorter than and almost as wide as scape.

Prothorax narrower than head, slightly longer than wide; meso- and metathorax robust, much wider than prothorax. Wings broad, ca. 3.5 times as long as wide, transparent and immaculate; single trichosor between veins along distal margin but 3-5 trichosors present between distal costal crossveins and branches of $\mathrm{CuA}$ and $\mathrm{CuP}$ in forewing, or branches of MP2 and CuA in hind wing.

Forewing: Wing base strongly narrowed, with a row of scaly setae on proximal section of costal vein, and a number of thick setae along proximal sections of ScP, MP, and A1; costal space gradually widened distally, nearly three times as wide as subcostal space, distally distinctly wider than radial space, with ca. 27 simple crossveins on proximal 2/3, and 21 crossveins and veinlets of $\mathrm{ScP}+\mathrm{RA}$ on distal 1/3, mostly marginally forked; subcostal crossveins absent; six presectoral crossveins present; RP + MA originating at proximal 1/3 of wing; RP pectinately branched from its proximal $1 / 5$, with one rp-ma crossvein between stem of RP and MA; RP with eight branches, mostly bearing a marginal fork; 16 crossveins present among branches of RP and MA on proximal half; a distal gradate series of crossveins present; MA slightly zig-zagged, with a marginal fork; MP long and straight, branched from distal 1/6, with six branches, mostly deeply forked; 17 crossveins present between MP and CuA; CuA slightly zig-zagged, pectinately branched at distal 1/3, with 10 simple branches; CuP and A1 proximally fused, distally zigzagged, terminating slightly distal to diverging point between RP and MA, pectinately branched into 14 simple branches; A2 approximating stem of A1, distally abruptly curved posteriad; A3 simple, with one a2-a3 crossvein.

Hind wing: Slightly longer and narrower than forewing, with base distinctly narrowed, and with apex acutely pointed and slightly bended posteriad; costal space nearly twice as wide as subcostal space, with 22 mostly simple crossveins on proximal 3/4 and 16 crossveins and veinlets of $\mathrm{ScP}+\mathrm{RA}$ on distal 1/4, mostly forked marginally; subcostal crossveins absent; five presectoral crossveins present; RP + MA originating at proximal 1/3 of wing; $\mathrm{RP}$ pectinately branched from its proximal 1/5 into eight branches, mostly bearing a marginal fork; one rp-ma 


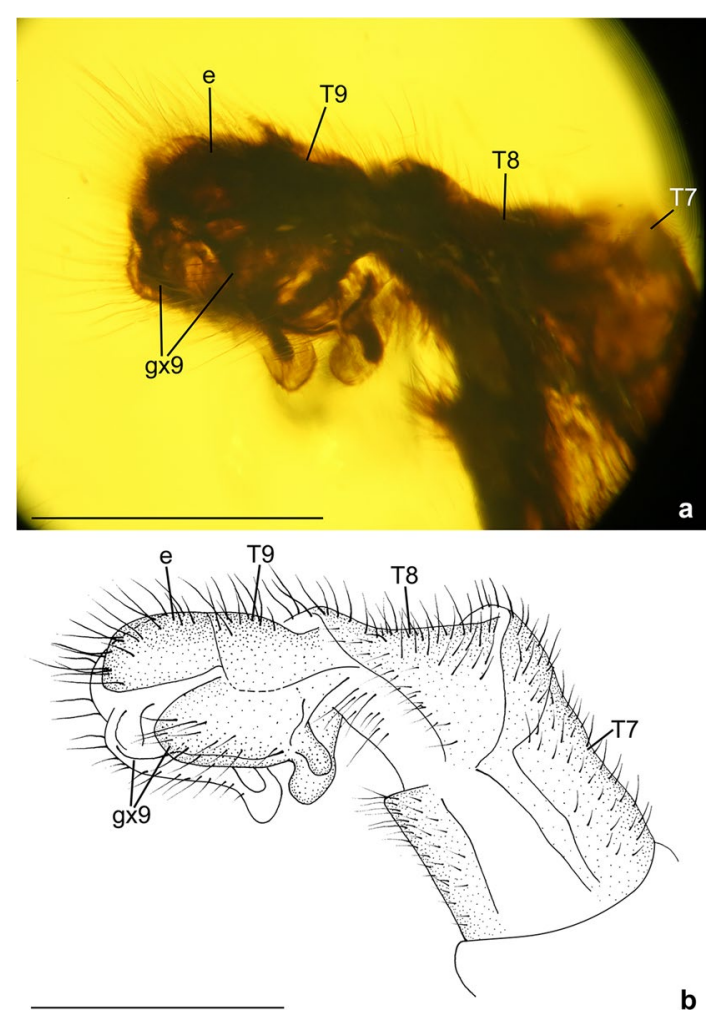

Figure 9. Xiaobabinskaia lepidotricha sp. nov., holotype female. (a) photograph of genitalia, lateral view; (b) drawing of genitalia, lateral view (drawn by XML). Scale bar $=1.0 \mathrm{~mm}$.

crossvein present between stem of RP and MA; eight crossveins present among branches of RP and MA on proximal half; a distal gradate series of crossveins present, with 10 corssveins; MP1 and MP2 diverging near wing base, long and slightly zig-zagged; MP1 pectinately branched distally, with six branches, each bearing a marginal fork; MP2 pectinately branched from distal 1/3, with 11 branches, most of which are simple except distal-most one bearing a small marginal fork; $\mathrm{CuA}$ long, with 11 simple branches, terminating at same level of diverging point between $\mathrm{RP}$ and MA; $\mathrm{CuP}$ and $\mathrm{A} 1$ possibly fused with $\mathrm{CuA}$.

Legs slender, with sparse short setae; a pair of tibial spurs present; tarsus 5-segmented; tarsomere 1 longest, nearly twice as long as tarsomere 2; tarsomeres 3-5 shortest, nearly half length of tarsomere 2; each tarsomere slightly widened distally; pretarsal claws slender and slightly curved, equal in length and shape; arolium not discernible.

Abdomen slenderly elongate, with segments 4-6 much broader. Female genitalia: Tergum 8 nearly as long as tergum 9 plus ectoproct; ventral sclerites of segment 8 not discernible; tergum 9 nearly rectangular in lateral view; a pair of broad valvate gonocoxites 9 present, proximally with a pair of short and flat lobes, which are rounded at tip; ectoprocts paired and broad, nearly rectangular in lateral view; callus cerci not discernible.

Etymology The specific epithet "lepidotricha" refers to the presence of a row of scaly setae on the proximal section of forewing costal vein in the new species.

Type material Holotype: CAM BA-0018. Amber piece preserving a nearly complete female adult of Xiaobabinskaia lepidotricha gen. et sp. nov. It is polished in the form of a flattened elliptical cabochon, clear and transparent, with length $\times$ width $40.08 \times 25.55 \mathrm{~mm}$, height $9.37 \mathrm{~mm}$.

Phylogenetic analysis. The maximum parsimony analysis in TNT yielded eight most parsimonious trees (MPTs) (length $=148$, consistency index $=47$, retention index $=81$ ). The strict consensus tree and comparison of main venational characters with phylogenetic relevance are shown in Figs. 10, 11 and S1. The presently recovered monophyletic Myrmeleontoidea is supported by the absence of forewing nygmata (character 5:1) and the forewing ScP and RA terminating at or posteriad wing apex (character 13:1). Nymphidae is recovered to be the sister group of the clade including the remaining genera, and its autapomorphies comprise the prothorax slightly elongated anteriad procoxae (3:1), the presence of forewing thrydiate crossveins (character 14:1) and the bifid arolium (character 50:1). The monophyly of the latter clade is supported by the forewing RP + MA diverging slightly distal to wing base (16:1), and the forewing $\mathrm{CuA}$ branched near midpoint of wing with 10 or more branches (characters 28:2 and 29:1). Cratosmylidae and Babinskaiidae are clustered together, being sister to the lineage of Nemopteridae + (Myrmeleontidae + Palaeoleontidae). The monophyly of Cratosmylidae + Babinskaii- 

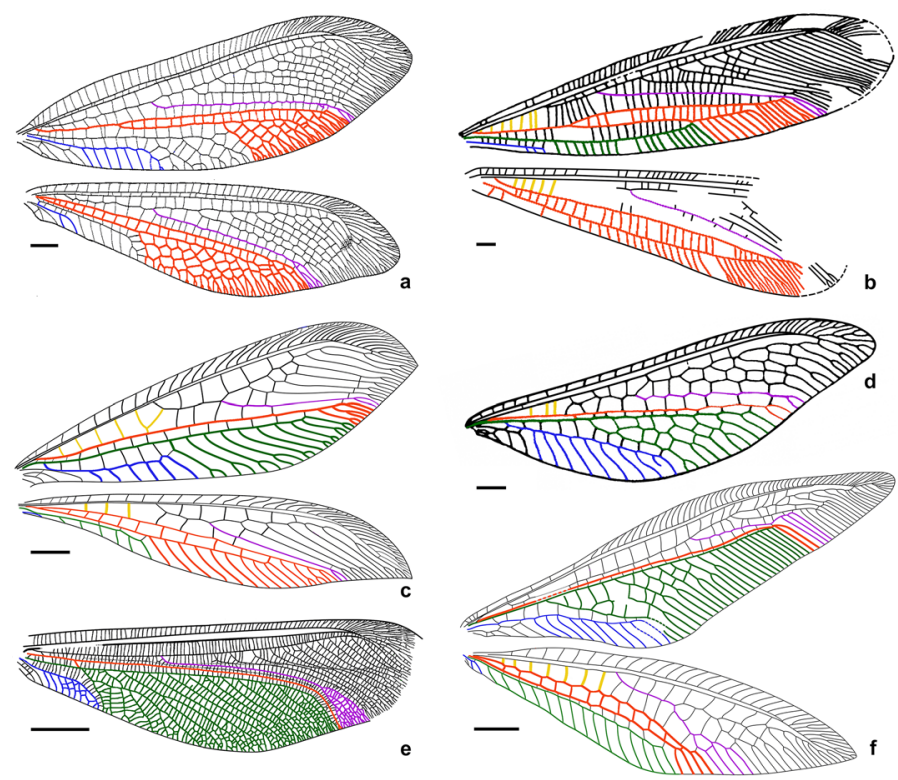

Figure 10. Comparison of wing venations among representatives of Myrmeleontoidea. (a) Nymphidae: Nesydrion nigrinerve Esben-Petersen ${ }^{54}$ (modified from $\mathrm{New}^{55}$, republished with permission of Australian Journal of Zoology, from A revision of the Australian Nymphidae (Insecta: Neuroptera), New, T. R., 29, $707-$ 750, 1981, permission conveyed through Copyright Clearance Center, Inc.). (b) Cratosmylidae: Araripenymphes seldeni Menon, Martins-Neto and Martill ${ }^{18}$ (drawn by XML); (c) Babinskaiidae: Electrobabinskaia burmana Lu et al. ${ }^{6}$ (drawn by XML); (d) Nemopteridae: Pastranaia riojana Orfila ${ }^{56}$ (forewing only, drawn by XML); (e) Palaeoleontidae: Parapalaeoleon magus Menon and Makarkin ${ }^{47}$ (forewing only, drawn by XML); (f) Myrmeleontidae: Phylloleon stangei Lu et al. ${ }^{22}$ (drawn by XML). Venations with presectoral crossveins (yellow), MA (purple), MP and oblique vein (red), CuA (green) and CuP (blue) highlighted. Scale bars = $1.0 \mathrm{~mm}(\mathbf{b}, \mathbf{c})$; $2.0 \mathrm{~mm}(\mathbf{a}, \mathbf{d}, \mathbf{f}) ; 5.0 \mathrm{~mm}(\mathbf{e})$.

dae is supported by the presence of more than two presectoral crossveins in both fore- and hind wings (characters $15: 2$ and 46:2), the reduction of crossveins on distal part of forewing radial space (21:1), the forewing $\mathrm{CuP}$ fused with A1 (38:1), hind wing RP + MA diverging from a position slightly distal to wing base (45:1), and the reduction of hind wing A2 and A3 (character 48:1). The two genera of Cratosmylidae did not form a monophylum. The assigned autapomorphies of Babinskaiidae include the RP + MA diverging from a position distinctly distal to wing base in both fore- and hind wings (15:2 and 45:2), and the single forewing MP (24:2). Within Babinskaiidae, Stenobabinskaia gen. nov. and Calobabinskaia gen. nov. are clustered together based on the presence of more than 10 presectoral crossveins in the forewing (character 15:3), the presence of trapezoidal forewing prehypostigmal cell (character 17:1), the forewing with distance between diverging point respectively of MA and RP1 twice as long as distance between diverging points respectively of RP1 and RP2 (22:1), the forewing MP1 terminating near wing apex (character 25:1), the forewing CuA branches marginally forked (character 31:1), and the extremely long forewing $\mathrm{CuP}$ (character 36:3). The remaining babinskaiid genera besides Xiaobabinskaia gen. nov. constitute another monophyletic group supported by the less crossveins in radial space (character 21:1) and the forewing CuP not fused with A1 (38:0), and together sister to Xiaobabinskaia gen. nov. by the zigzagged forewing $\mathrm{CuP}(37: 1)$.

The monophyly of Nemopteridae + (Palaeoleontidae + Myrmeleontidae) is supported by the absence of trichosors (character 4:1), the single forewing MP (24:2), the presence of forewing oblique vein (character 27:1), and the subtriangular bra nching area of MP2 + CuA (character 30:1). The autapomorphies of Nemopteridae comprise the presence of prolonged rostrum (character 2:1), the closely spaced forewing $\mathrm{CuA}$ and $\mathrm{CuP}$ (character 34:1), and the strongly narrowed and elongated hind wing (characters 41:2 and 42:2). The monophylum including the genera of Myrmeleontidae and Palaeoleontidae is recovered based on the presence of short forewing $\mathrm{CuA} 2$ (character 32:1) and short hind wing $\mathrm{CuP}$ (character 36:0). The monophyly of Palaeoleontidae is supported based on the forewing RP + MA diverging from a positon near wing base (16:0), the short forewing hypostigmal cell (character 18:0), the forewing radial space with a Banksian line (character 20:1) and the pectinately branched forewing CuA2 with 3-4 branches (33:1). The monophyly of Myrmeleontidae is supported by the strongly dilated antennae (character 1:2), the origin of RP + MA slightly distal to wing base (character 45:1), and the presence of prolonged tibial spur (character 49:1). Within Myrmeleontidae, the extant three subfamilies form a monophyletic clade, being sister to another clade including Pseudonymphinae and Araripeneurinae. Araripeneurinae is nested in a clade including some Cretaceous antlion genera, i.e., Choromyrmeleon Ren and Guo ${ }^{16}$, Nanoleon Hu, Lu and Liu in Lu et al. ${ }^{6}$ and Burmaneura Huang et al. ${ }^{17}$.

The overall nodal supports are not strong if considering the Bremer support values/Bootstrap values, which is probably due to the large proportion of missing characters in the fossil taxa. However, weak support does not 


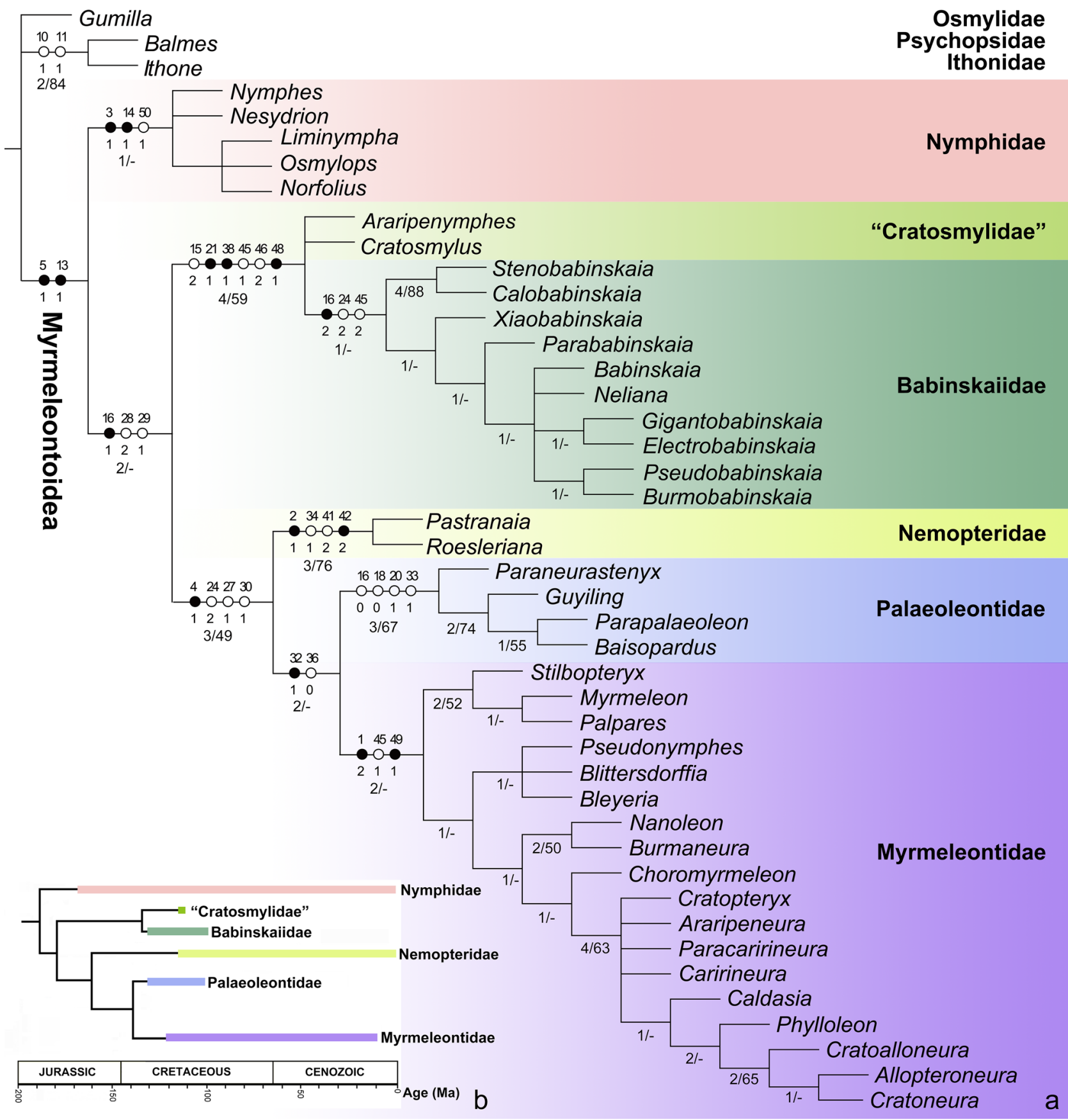

Figure 11. Phylogeny and evolutionary chronogram of extinct and extant Myrmeleontoidea. (a) Topology represents the strict consensus tree of the eight most parsimonious trees yielded from TNT v1.5 (www.zmuc. $\mathrm{dk} /$ public/phylogeny ${ }^{52}$ (see more detail information in supplementary material, Fig. S1). Unambiguous state changes of the morphological characters at the familial and higher level are shown on the tree. Black circle represents the homologous state and white circle represents the homoplasious state. Bremer support values/ Bootstrap values are shown at relevant nodes. (b) Scheme of the interfamilial phylogeny of Myrmeleontoidea based on present result, thick lines indicate known geological distributions.

always mean unreliable relationships, as the monophyly of many groups, such as Nymphidae and Nemopteridae, were recovered based on a number of apomorphic character states although these groups received low nodal support.

\section{Discussion}

Monophyly of Babinskaiidae. Babinskaiidae is a well-defined fossil myrmeleontoid family by a series of adult characters (see familial diagnosis in "Systematic palaeontology") although the larvae of this family have not yet been reported. However, the autapomorphy of this family is not conspicuous. Martins-Neto ${ }^{13}$ first proposed 
three apomorphic characters of this family: (1) the forewing MP2 + CuA1 (i.e., CuA in this paper) reaching the apical margin, (2) the origin of forewing RP (i.e., RP + MA in this paper) far from wing base, and (3) the zigzagged forewing CuP. Makarkin et al. (2017) refuted the above characters 1 and 3 to be apomorphic, and outlined four apomorphic characters, i.e., the origin of forewing RP far from wing base (the above character 2), the presence of presectoral crossveins, the single forewing MP, and the reduction of hind wing A2 and A3. Among these characters, only the last character is considered to be the autapomorphy of Babinskaiidae ${ }^{7}$. In Makarkin and Staniczek ${ }^{10}$, however, this autapomorphy was modified to be the very small anal space and the reduction of A3 in the hind wing because distinct hind wing A2 is found in Parababinskaia makarkini Hu et al. ${ }^{8}$ and Electrobabinskaia burmana Lu et al. , $^{6.8}$

In the present result of phylogenetic analysis, some putative autapomorphies of Babinskaiidae mentioned above (e.g., the presence of more than two presectoral crossveins in both fore- and hind wings and the reduced hind wing A2 and A3) turned to be the autapomorphies of Cratosmylidae + Babinskaiidae. Cratosmylidae is composed of two genera from the Lower Cretaceous of Brazil, i.e., Araripenymphes Menon et al. ${ }^{18}$ and Cratosmylus Myskowiak et al. ${ }^{7,19}$. The former taxon is placed within Nymphidae ${ }^{18,19}$. This latter taxon was originally established as a subfamily of Osmylidae ${ }^{19}$, but later transferred to Nymphidae by Winterton et al. ${ }^{20}$. The two genera were considered to represent a separate family Cratosmylidae by Makarkin et al. ${ }^{7}$. Cratosmylidae appears to be a transitional lineage between Nymphidae and Babinskaiidae because it has an intermediate type of characters (Fig. 11). For example, Cratosmylidae and Nymphidae have a more or less proximal position of the forewing $\mathrm{RP}+\mathrm{MA}$ origin and a deeply branched forewing MP, while Cratosmylidae and Babinskaiidae have several presectoral crossveins. Our result supports that Araripenymphes and Cratosmylus should not belong to Nymphidae (Fig. 11, S1). The closer relationship between Cratosmylidae and Babinskaiidae, as well as the paraphyly of the former family herein recovered, invokes another option that these two taxa may constitute a single family, with Cratosmylidae treated to be a subfamily of Babinskaiidae, as they share some similar apomorphic characters. Nevertheless, due to the scarcity of the cratosmylid fossils, we here retain the current classification until more materials are available for further evaluation.

Phylogenetic position of Babinskaiidae. In the phylogenetic analysis of Myrmeleontoidea combining fossil and extant families ${ }^{13}$, Babinskaiidae was recovered to be the sister group of the clade including most myrmeleontoid families except Nymphidae, which is supported by the presence of forewing presectoral crossveins and forewing MP2 fused with CuA1. However, the forewing presectoral crossveins is absent in many genera of the families/subfamilies within the above clade, such as Araripeneurinae, Pseudonymphinae, Palaeoleontidae, etc. Besides, no oblique vein that is indicative of the fusion between forewing MP2 and CuA1 is found in any babinskaiids $^{6,7,21,22}$. Our result is generally consistent with that in Martins-Neto ${ }^{13}$ concerning the position of Babinskaiidae + Cratosmylidae. However, the sister-group relationship between Babinskaiidae + Cratosmylidae and Nemopteridae + (Myrmeleontidae + Palaeoleontidae) is herein supported by the forewing RP + MA diverging from a position slightly distal to wing base, the forewing $\mathrm{CuA}$ initially branched near the midpoint of wing, and the forewing $\mathrm{CuA}$ with 10 or more branches. Nonetheless, this argument is also not strong enough because the second character state is also present in some genera of Nymphidae and the third character state is absent in most antlions. Given the complex and sometimes unpredictable evolutionary pattern of insect wing venations $\mathrm{s}^{23}$, the presently used wing characters may not provide sufficient phylogenetic signal to resolve the higher phylogeny of Myrmeleontoidea, especially including many fossil taxa. However, the morphological arguments in Makarkin et al. ${ }^{7}$ placing Babinskaiidae together with Nymphidae in Nymphidoidae, i.e., the presence of trichosors and the completely separated forewing MP and $\mathrm{CuA}$, are obviously attributed to the plesiomorphic condition in Neuroptera, which was also mentioned by these authors. Therefore, the phylogenetic position of Babinskaiidae herein recovered is still preferable, but awaits further evidence for corroboration.

Besides the adult characters, the larval morphology of Myrmeleontoidea also provides an important set of characters that are phylogenetically informative ${ }^{24}$. So far, no definite larva of Babinskaiidae has been reported. Badano et al. ${ }^{25}$ presented an interesting study focusing on the higher phylogeny of Myrmeleontiformia by using larval characters from both extant and fossil taxa. Notably, most fossil taxa sampled for the phylogenetic analysis in Badano et al. ${ }^{25}$ are from Kachin amber. Thus, this work is highly relevant to the present study and may provide additional evidence to infer the phylogenetic position of Babinskaiidae. Babinskaiidae is the most diverse and abundant group of Myrmeleontoidea from Kachin amber ${ }^{1}$. In the phylogeny recovered in Badano et al. ${ }^{25}$, the diverse Kachin amber myrmeleontoids without definite familial affiliations (e.g., Electrocaptivus xui Badano, Engel and Wang in Badano et al. ${ }^{25}$, Burmitus tubulifer Badano, Engel and Wang in Badano et al..$^{25}$, Adelpholeon lithophorus Badano and Engel in Badano et al., 2018 25 , etc.) are assigned to be the stem-group Ascalaphidae + Myrmeleontidae, while there is no stem-group taxon or "side branch" found for Nymphidae as mentioned in Makarkin et al. ${ }^{7,21}$. Taphonomically, the diverse Kachin amber myrmeleontoid larvae that do not belong to any extant family may be associated with the extinct family Babinskaiidae, which is also diverse in species from the same deposit. Following this assumption, in the phylogenetic tree of Badano et al. ${ }^{24}$, Babinskaiidae is nested within the clade including Nemopteridae, Ascalaphidae, and Myrmeleontidae, which is partially concordant to the present result, although the identical position and monophyly of Babinskaiidae is not recovered as in our result. Of course, there are other possibilities on the identity of these larvae, such as those of the extinct Araripeneurinae that are also relatively basal to the extant antlions. Future in-depth study on the taxonomy of the Kachin amber myrmeleontoid larvae and their associations with the adult forms is important to resolve the deep phylogeny of Myrmeleontoidea.

Diversification of Babinskaiidae. The new babinskaiids from Kachin amber highlight the early diversification of this Cretaceous lacewing lineage. Besides the rich species diversity, the Kachin amber babinskaiids, 
currently comprising nine genera and 10 species, display diverse morphological characters (Table S1). Pseudobabinskaia martinsnetoi (Lu et al. ${ }^{6}$ is known to date as the smallest species of the family in body-size (forewing length $9.0 \mathrm{~mm}$ ), while C. xiai sp. nov. and Gigantobabinskaia godunkoi Makarkin and Staniczek ${ }^{10}$ are among the largest babinskaiids (forewing length over $22.0 \mathrm{~mm}$ ) ${ }^{6} 10$. Specialized wing shape is also remarkable in some Kachin amber babinskaiids. For example, C. xiai sp. nov. and S. punctata sp. nov. possess distinctly narrow and elongate wings; E. burmana, G. godunkoi, and X. lepidotricha sp. nov. have modified hind wings that are distally falcate; and more peculiarly Burmobabinskaia tenuis Lu et al. ${ }^{6}$ has strongly narrowed hind wing similar to that of Nemopteridae ${ }^{6,10}$.

The morphological diversity of legs are highlighted by the differently modified tarsi and arolium. The tarsomeres are usually dilated in many babinskaiids, being indicative of an arboreal life mode, but the degree of development greatly varies among species ${ }^{10}$. In G. godunkoi all five metatarsomeres are strongly dilated with long hairs ${ }^{10}$. A similar trait is also present in E. burmana, but being slightly less developed ${ }^{6}$. In the other Burmese amber babinskaiids, such tarsal dilation is not as distinct as the former two species. However, in C. xiai sp. nov. the tarsomeres of all legs are densely setose and bear several long spinous, distally directed setae on the ventral surface. More interestingly, this species has bifid arolium in all legs, suggesting that this character state previously considered to be an autapomorphy of Nymphidae ${ }^{26}$ is convergently derived in other myrmeleontoid species. Additionally, in C. xiai sp. nov. there are some regularly spaced spinous setae on femora and tibiae, which seemingly function for predation or defense.

The scaly setae on the basal section of forewing costa in X. lepidotrica sp. nov. is another striking trait (Figs. 7, 8). This is not only the first report of scales in Babinskaiidae but also in all fossil and extant myrmeleontoids. Such scales especially resemble those in some beaded lacewings (Neuroptera: Berothidae). So far, function of the scales in Berothidae is completely unknown, however, in this family these scales are only found in females ${ }^{27-29}$. Thus, the scales in female beaded lacewings may be a kind of organs related to chemical communication for attracting or searching mates. Notably, the scales in babinskaiids herein reported are also present in female. Although the male of X. lepidotrica sp. nov. has not been found, if the scales are absent in males of this species, similar function of this trait involved in courtship as hypothesized in Berothidae may be inferred. Nevertheless, convincing evidence awaits discovery. Scales are also present on the wing eyespot of some derived subfamilies of Kalligrammatidae, which is thought to have certain optical function ${ }^{30}$. It is evident that they may be not similar in form and function to the presently reported scales in Babinskaiidae. In the nemopterid subfamily Crocinae, some extant species have a specialized structure called "bulla", which is a group of silky hairs, sometimes ended as a small knob, on the fore- or hind wings ${ }^{31}$. This trait is confined to males and thought to be a kind of scent $\operatorname{organ}^{31}$. Similarly, the pilula axillaris or Eltringham organ is a club-like projection laterally with a tuft of setae from the hind wing margin, and it is also confined to male antlions. However, this structure is proposed to be a dispersing organ that could spread but not produce the sexual pheromones ${ }^{32}$. In some fossil species of the extinct chrysopoid family Mesochrysopidae there is a bunch of elongated hairs on the forewing ${ }^{33}$. Possibly, this trait also has a similar function as the scales or specialized hairs or organ in aforementioned myrmeleontoids, although whether it is present in only male or female or both sexes is unknown.

Finally, it is noteworthy to mention some previously unknown characters of the female genitalia in Babinskaiidae. In C. xiai sp. nov. the valvate female gonocoxites 9 bear some short dentoid processes along the ventral margin. In many antlions there are a number of stiff setae called digging setae on some female genital sclerites, such as gonocoxites 8 , gonocoxites 9 , and ectoprocts ${ }^{34,35}$. This is an adaptive trait for laying eggs on sand-like substrate ${ }^{34,35}$, which is probably associated with the fossorial life-style of some antlion larvae. In X. lepidotrica sp. nov. there is an additional lobe on anteroventral portion of the female gonocoxite 9 , and this modification is similar to the hypocaudae in some berothid species ${ }^{28}$. In total, five types of female genitalia have thus far been described in Babinskaiidae (see Lu et al. ${ }^{6}$; Hu et al. ${ }^{8}$ ), suggesting disparate copulation or oviposition behaviors of these archaic myrmeleontoid species.

\section{Conclusion}

The palaeofauna of Babinskaiidae from the mid-Cretaceous Kachin amber of Myanmar is represented by diverse genera and species with disparate morphological modifications. Our findings provide significant new morphological evidence for understanding the phylogenetic position and diversity of Babinskaiidae. In terms of the phylogenetic position of Babinskaiidae herein recovered, this Cretaceous family probably represents a transitional lineage between Nymphidae and the advanced myrmeleontoids. The Cretaceous radiation and recent decline of Babinskaiidae remains mysterious, awaiting discovery of palaeodiversity and phylogenetic study combining adult and larval characters.

\section{Material and methods}

Taxonomy. The amber specimens described herein are from the Hukawng Valley, Tanai Township, Myitkyina District, Kachin State, Myanmar (see Kania et al. ${ }^{36}$ : Fig. 1). The age of this deposit is dated to be $\sim 99$ million years (the earliest Cenomanian) by $\mathrm{U}-\mathrm{Pb}$ dating of zircons from the volcaniclastic matrix of the amber ${ }^{37}$.

The type specimens are deposited in the Nanjing Institute of Geology and Palaeontology (NIGP), Chinese Academy of Sciences, Nanjing; the Lingpoge Amber Museum (LAM), Shanghai; and the Century Amber Museum (CAM), Shenzhen.

Photographs and drawings were taken and made using a Leica M125C microscope system connecting with a Canon EOS 5D Mark IV camera system. The figures were prepared with Adobe Photoshop CS6. Terminology of wing venation generally follow Aspöck et al. ${ }^{38}$ and Martins-Neto ${ }^{39}$. Terminology of genitalia follows Aspöck and Aspöck ${ }^{40}$. 
Abbreviations used for wing veins are: $\mathrm{A}$, anal vein; $\mathrm{C}$, costa; $\mathrm{Cu}$, cubitus; $\mathrm{CuA}$, cubitus anterior; $\mathrm{MP}$, media posterior; R, radius; RA, radius anterior; RP, radius posterior; $\mathrm{ScA}$, subcosta anterior; $\mathrm{ScP}$, subcosta posterior; ps, presectoral crossveins (i.e., r-mp crossveins).

All taxonomic acts established in this paper have been registered in ZooBank, together with the electronic publication: urn:lsid:zoobank.org:pub:605A4DCC-9ADE-473C-93BD-31878E03FA07.

Phylogenetic analysis. Aiming to reveal the phylogenetic position of Babinskaiidae within Myrmeleontoidea, a phylogenetic analysis was performed based on samples from major fossil and extant lineages of Myrmeleontoidea. For the ingroup taxa in the present analysis, we sampled most known genera of Babinskaiidae except Baisonelia (only hind wings preserved) and Pseudoneliana (distal part of both wings not preserved). For Nymphidae, the stem-group of this family (Liminympha Ren and Engel ${ }^{41}$ ) as well as the extant representatives of Nymphinae (Nesydrion Gerstaecker ${ }^{42}$ and Nymphes Leach ${ }^{43}$ ) and Miodactylinae (Osmylops Banks ${ }^{44}$ and Norfolius Navás ${ }^{45}$ ) were selected. Two nymphid-like genera from the Lower Cretaceous of Brazil, i.e., Araripenymphes and Cratosmylus, which were considered to represent a separate family Cratosmylidae by Makarkin et al. ${ }^{7}$, were selected. Three genera of the extinct family Palaeoleontidae, i.e., Baisopardus Ponomarenko ${ }^{4}$, Paraneurastenyx Martins-Neto ${ }^{46}$, and Parapalaeoleon Menon and Makarkin ${ }^{47}$, were selected because the species of these genera have better preserved morphological characters than the other species of this poorly known myrmeleontoid fossil family. The other sampled ingroup taxa are the same to those in Lu et al. ${ }^{22}$. Notably, the genera Stilbopteryx and Palpares are assigned to the subfamily Ascalaphinae in Machado et al. ${ }^{48}$, representing ascalaphids in the present sampling. We selected Gumilla Navás ${ }^{49}$ (Osmylidae), Ithone Newman ${ }^{50}$ (Ithonidae) and Balmes Navás ${ }^{51}$ (Psychopsidae) as the outgroup taxa.

Morphological characters used in the phylogenetic analysis are mainly from Martins-Neto ${ }^{13,14}$ and Lu et al. ${ }^{22}$ with some modification, comprising a total of 54 adult characters (see Note S1). Unknown characters were coded as "?", while inapplicable characters were coded as “-”. The data matrix is also given in Table S2. All characters were treated as unordered and with equal weight. We analyzed the dataset using TNT v1.5 ${ }^{52}$ with an initial Traditional search (Starting trees: 100 repls, TBR, trees to save per replication: 10). Bremer support values and Bootstrap values were calculated with the function implemented in TNT (Setting for Bremer support values calculation: TBR from existing trees, retain trees suboptimal by 10 steps; setting for Bootstrap values calculation: traditional search, number of replicates: 1000). Character states were mapped on the strict consensus tree (MPT) using WinClada ver. $1.00 .08^{53}$, showing only unambiguous changes.

Received: 10 March 2021; Accepted: 2 August 2021

Published online: 12 August 2021

\section{References}

1. Lu, X.-M. \& Liu, X.-Y. The Neuropterida from the mid-Cretaceous of Myanmar: A spectacular palaeodiversity bridging the Mesozoic and present faunas. Cret. Res. 121, 104727 (2021).

2. Martins-Neto, R. G. \& Vulcano, M. A. Neuropteros (Insecta, Planipennia) da Formaçao Santana (Cretaceo Inferior), bacia do Araripe, nordeste do Brasil II. Superfamília Myrmeleontoidea. Revta. Bras. Entomol. 33, 367-402 (1989).

3. Martins-Neto, R. G. \& Vulcano, M. A. Neurópteros (Insecta, Planipennia) da Formaçao Santana (Cretáceo Inferior), Bacia do Araripe, nordeste do Brasil. IV - Complemento às partes I e II, com descriçao de novos taxa. An. Acad. Bras. Ci. 61, 311-318 (1989).

4. Ponomarenko, A. G. Neuroptera (Insecta) from the Lower Cretaceous of Transbaikalia. J. Paleontol. 3, 43-50 (1992).

5. Martins-Neto, R. G. Neurópteros (Insecta, Planipennia) da Formaçao Santana (Cretáceo Inferior), Bacia do Araripe, Nordeste do Brasil. X - Descriçao de novos táxons (Chrysopidae, Babinskaiidae, Myrmeleontidae, Ascalaphidae e Psychopsidae). R. Uni. Guar., Ci. Exat. Technol. 2, 68-83 (1997).

6. Lu, X.-M., Zhang, W.-W. \& Liu, X.-Y. Discovery of the family Babinskaiidae (Insecta: Neuroptera) in mid-Cretaceous amber from Myanmar. Cret. Res. 71, 14-23 (2017).

7. Makarkin, V. N., Heads, S. W. \& Wedmann, S. Taxonomic study of the Cretaceous lacewing family Babinskaiidae (Neuroptera: Myrmeleontoidea: Nymphidoidae), with description of new taxa. Cret. Res. 78, 149-160 (2017).

8. Hu, J.-H., Lu, X.-M., Wang, B. \& Liu, X.-Y. Taxonomic notes on Babinskaiidae from the Cretaceous Burmese amber, with the description of a new species (Insecta, Neuroptera). ZooKeys 748, 31-46 (2018).

9. Huang, D.-Y., Nel, A. \& Azar, D. An additional new taxon belonging to the small Cretaceous lacewing family Babinskaiidae (Insecta: Neuroptera: Myrmeleontoidea) from the Burmese amber. Cret. Res. 101, 43-46 (2019).

10. Makarkin, V. N. \& Staniczek, A. H. A new large-sized genus of Babinskaiidae (Neuroptera: Myrmeleontoidea: Nymphidoidae) from mid-Cretaceous Burmese amber. Cret. Res. 104, 104196 (2019).

11. Ngô-Muller, V., Garrouste, R., Pouillon, J. M., Douteau, J. \& Nel, A. A new Babinskaiidae from the 'mid'-Cretaceous Burmese amber (Insecta, Neuroptera, Myrmeleontoidea). Cret. Res. 2020, 104478 (2020).

12. Martins-Neto, R. G. Neurópteros (Insecta, Planipennia) da Formaçao Santana (Cretáceo Inferior) Bacia do Araripe, Nordeste do Brasil. V: Aspectos filogenéticos, paleoecológicos, paleobiogeogr ficos e descriçao de novos taxa. An. Acad. Bras. Ci. 64, 117-148 (1992).

13. Martins-Neto, R. G. The Santana formation paleoentomofauna reviewed. Part I: Neuropteroida (Neuroptera and Raphidioptera): systematic and phylogeny, with description of new taxa. Acta Geol. Leopoldensia (R.S.) 25, 35-66 (2002).

14. Martins-Neto, R. G. New Neuroptera from Crato formation, Lower Cretaceous, Araripe Basin, northeast Brazil. GAEA 1, 5-10 (2005).

15. Yang, Q., Makarkin, V. N., Winterton, S. L., Khramov, A. V. \& Ren, D. A remarkable new family of Jurassic insects (Neuroptera) with primitive wing venation and its phylogenetic position in Neuropterida. PLoS ONE 7, 1-38 (2012).

16. Ren, D. \& Guo, Z.-G. On the new fossil genera and species of Neuroptera (Insecta) from the Late Jurassic of northeast China. Acta Zootaxon. Sin. 21, 461-479 (1996).

17. Huang, D.-Y. et al. The first araripeneurine antlion in Burmese amber (Neuroptera: Myrmeleontidae). Cret. Res. 63, 1-6 (2016).

18. Menon, F., Martins-Neto, R. G. \& Martill, D. M. A new Lower Cretaceous nymphid (Insecta, Neuroptera, Nymphidae) from the Crato Formation of Brazil. GAEA 1, 11-15 (2005).

19. Myskowiak, J., Escuillié, F. \& Nel, A. A new Osmylidae (Insecta, Neuroptera) from the Lower Cretaceous Crato Formation in Brazil. Cret. Res. 54, 27-33 (2015). 
20. Winterton, S. L., Califre Martins, C., Makarkin, V. N., Ardila Camacho, J. A. \& Wang, Y.-J. Lance lacewings of the world (Neuroptera: Archeosmylidae, Osmylidae, Saucrosmylidae): review of living and fossil genera. Zootaxa 4581, 1-99 (2019).

21. Makarkin, V. N., Wedmann, S. \& Heads, S. W. A systematic reappraisal of Araripeneuridae (Neuroptera: Myrmeleontoidea), with description of new species from the Lower Cretaceous Crato Formation of Brazil. Cret. Res. 84, 600-621 (2018).

22. Lu, X.-M. et al. New antlions (Insecta: Neuroptera: Myrmeleontidae) from the mid-Cretaceous of Myanmar and their phylogenetic implications. J. Syst. Palaeontol. 17, 995-1012 (2019).

23. Kukalová-Peck, J. Phylogeny of higher taxa in Insecta: finding synapomorphies in the extant fauna and separating them from homoplasies. Evol. Biol. 35, 4-51 (2008).

24. Badano, D., Aspöck, U., Aspöck, H. \& Cerretti, P. Phylogeny of Myrmeleontiformia based on larval morphology (Neuropterida: Neuroptera). Syst. Entomol. 42, 94-117 (2017).

25. Badano, D., Engel, M. S., Basso, A., Wang, B. \& Cerretti, P. Diverse Cretaceous larvae reveal the evolutionary and behavioural history of antlions and lacewings. Nat. Comm. 9, 1-14 (2018).

26. Shi, C.-F., Winterton, S. L. \& Ren, D. Phylogeny of split-footed lacewings (Neuroptera, Nymphidae), with descriptions of new Cretaceous fossil species from China. Cladistics 31, 455-490 (2015).

27. Aspöck, U., Liu, X.-Y. \& Aspöck, H. The Berothidae of Taiwan (Neuroptera: Neuropterida). Dtsch. Entomol. Z. 60, 221-230 (2013).

28. Aspöck, U. \& Randolf, S. Beaded lacewings: A pictorial identification key to the genera, their biogeographics and a phylogentic analysis (Insecta: Neuroptera: Berothidae). Dtsch. Entomol. Z. 61, 155-172 (2014).

29. Li, D., Aspöck, H., Aspöck, U. \& Liu, X.-Y. New beaded lacewings (Insecta: Neuroptera: Berothidae) from Indochina. Zootaxa 4890, 509-520 (2020).

30. Labandeira, C. C. et al. The evolutionary convergence of mid-Mesozoic lacewings and Cenozoic butterflies. Proc. R. Soc. B 282, 20152893 (2016).

31. Tjeder, B. Neuroptera-Planipennia. The Lace-wings of Southern Africa. 6. Family Nemopteridae. pp. 290-501 in Hanström, B., Brinck, P. \& Rudebec, G. (eds.). South African Animal Life. Vol. 13. Swedish Natural Science Research Council, Stockholm (1967).

32. Elofsson, R. \& Löfqvist, J. The Eltringham organ and a new thoracic gland: ultrastructure and presumed pheromone function (Insecta, Myrmeleontidae). Zool. Scr. 3, 31-40 (1974).

33. Nel, A., Delclòs, X. \& Hutin, A. Mesozoic chrysopid-like Planipennia: a phylogenetic approach (Insecta: Neuroptera). Ann. Soc. Entomol. Fr. 41, 29-68 (2005).

34. Stange, L. A. Reclassification of the New World antlion genera formerly included in the tribe Brachynemurini (Neuroptera: Myrmeleontidae). Insecta Mundi 8, 67-119 (1994).

35. Stange, L. A. A systematic catalog, bibliography and classification of the world antlions (Insecta: Neuroptera: Myrmeleontidae). Mem. Am. Entomol. Inst. 74, [iv]+565 (2004).

36. Kania, I., Wang, B. \& Szwedo, J. Dicranoptycha Osten Sacken, 1860 (Diptera, Limoniidae) from the earliest Cenomanian Burmese amber. Cret. Res. 52, 522-530 (2015).

37. Shi, G. H. et al. Age constraint on Burmese amber based on U-Pb dating of zircons. Cret. Res. 37, 155-163 (2012).

38. Aspöck, H., Aspöck, U. \& Hölzel, H. Die Neuropteren Europas (2 vols). Goecke and Evers, Krefeld, West Germany, 495 pp (vol. 1), $355 \mathrm{pp}$ (vol. 2) (1980).

39. Martins-Neto, R. G. Remarks on the neuropterofauna (Insecta, Neuroptera) from the Brazilian Cretaceous, with keys for the identification of the known taxa. Acta Geol. Hisp. 35, 97-118 (2000).

40. Aspöck, U. \& Aspöck, H. Phylogenetic relevance of the genital sclerites of Neuropterida (Insecta: Holometabola). Syst. Entomol. 33, 97-127 (2008).

41. Ren, D. \& Engel, M. S. A split-footed lacewing and two epiosmylines from the Jurassic of China (Neuroptera). Ann. Zool. 57, 211-219 (2007).

42. Gerstaecker, A. Zwei fernere Decaden Australischer Neuroptera Megaloptera. Mitt. Naturwissenschaft. Verein Neu-Vorpommern und Rugen 16, 84-116 (1885).

43. Leach, W. E. Zoological Miscellany; Being Descriptions of New, or Interesting Animals. Vol. 1. (London, 1814).

44. Banks, N. Synopses and descriptions of exotic Neuroptera. Trans. Am. Entomol. Soc. 39, 201-242 (1913).

45. Navás, L. Insectos nuevos o poco conocidos. Mem. Real Acad. Ci. Art. Barca. 17, 383-400 (1922).

46. Martins-Neto, R. G. Neurópteros (Insecta, Planipennia) da Formaçao Santana (Cretáceo Inferior) Bacia do Araripe, Nordeste do Brasil - XI - Descriçao de novos táxons de Myrmeleontidae (Palaeoleontinae e Pseudonymphinae). R. Uni. Guar., Ci. Biol. Saúde 3, 38-42 (1998).

47. Menon, F. \& Makarkin, V. N. New fossil lacewings and antlions (Insecta, Neuroptera) from the Lower Cretaceous Crato Formation of Brazil. Palaeontology 51, 149-162 (2008)

48. Machado, R. J. P. et al. Owlflies are derived antlions: anchored phylogenomics supports a new phylogeny and classification of Myrmeleontidae (Neuroptera). Syst. Entomol. 44, 418-450 (2019).

49. Navás, L. Insectos neurópteros nuevos o poco conocidos. Mem. Real Acad. Ci. Art. Barca. 10, 135-202 (1912).

50. Newman, E. Entomological notes. Entomol. Mag., LDN. 5, 168-181, 372-402, 483-500 (1838).

51. Navás, L. Hemeróbidos (Ins. Neur.) nuevos con la clave de las tribus y géneros de la familia. Brotéria (Zool.) 9, 69-90 (1910).

52. Goloboff, P. A. \& Catalano, S. A. TNT version 1.5, including a full implementation of phylogenetic morphometrics. Cladistics 3 , 221-238 (2016).

53. Nixon, K. C. WinClada ver. 1.00.08. (Ithaca, Published by the author, 2002).

54. Esben-Petersen, P. Australian Neuroptera. Part i. Proc. Linn. Soc. NSW. 39, 635-645 (1914).

55. New, T. R. A revision of the Australian Nymphidae (Insecta: Neuroptera). Aust. J. Zool. 29, 707-750 (1981).

56. Orfila, R. N. Un nuevo Nemopteridae (Neuropt.) americano con una sinopsis de la familia. R. Soc. Entomol. Arg. 17, 29-32 (1954).

\section{Acknowledgements}

We cordially thank Mrs. Xiao Jia and Mr. Fangyuan Xia for their generosity in kindly providing the valuable pieces of amber examined in the present study. Sincere thanks go to Dr. Catherine L. Sole, Dr. Louwrens P. Snyman, and an anonymous referee who carefully read the manuscript and offered valuable suggestions for improvement of this work. The present study was funded by the National Natural Science Foundation of China (Nos. 31900348, 31972871, 31672322, 41688103) and the Shanghai Sailing Program (19YF1443000).

\section{Author contributions}

X.M.L. and X.Y.L. conceived this study, X.M.L., B.W. and X.Y.L. prepared the material, X.M.L. and X.Y.L. analyzed the data, all authors wrote the manuscript.

\section{Competing interests}

The authors declare no competing interests. 


\section{Additional information}

Supplementary Information The online version contains supplementary material available at https://doi.org/ 10.1038/s41598-021-95946-Z.

Correspondence and requests for materials should be addressed to X.L. or X.L.

Reprints and permissions information is available at www.nature.com/reprints.

Publisher's note Springer Nature remains neutral with regard to jurisdictional claims in published maps and institutional affiliations.

(c) (1) Open Access This article is licensed under a Creative Commons Attribution 4.0 International cc) License, which permits use, sharing, adaptation, distribution and reproduction in any medium or format, as long as you give appropriate credit to the original author(s) and the source, provide a link to the Creative Commons licence, and indicate if changes were made. The images or other third party material in this article are included in the article's Creative Commons licence, unless indicated otherwise in a credit line to the material. If material is not included in the article's Creative Commons licence and your intended use is not permitted by statutory regulation or exceeds the permitted use, you will need to obtain permission directly from the copyright holder. To view a copy of this licence, visit http://creativecommons.org/licenses/by/4.0/.

(C) The Author(s) 2021 